ORNL-3311

UC-34 - Physics

TID-4500 (18th ed.)

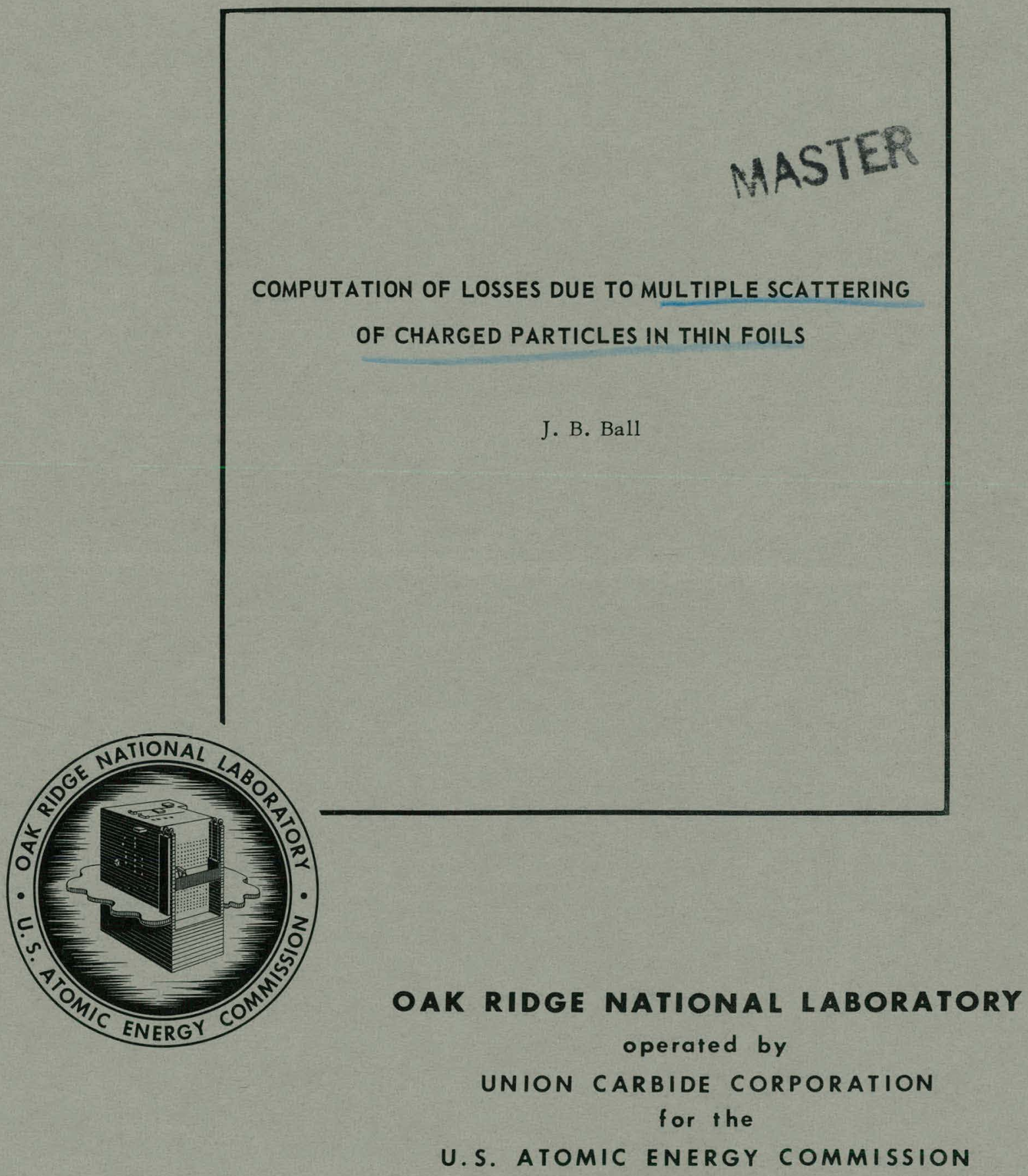




\section{DISCLAIMER}

This report was prepared as an account of work sponsored by an agency of the United States Government. Neither the United States Government nor any agency Thereof, nor any of their employees, makes any warranty, express or implied, or assumes any legal liability or responsibility for the accuracy, completeness, or usefulness of any information, apparatus, product, or process disclosed, or represents that its use would not infringe privately owned rights. Reference herein to any specific commercial product, process, or service by trade name, trademark, manufacturer, or otherwise does not necessarily constitute or imply its endorsement, recommendation, or favoring by the United States Government or any agency thereof. The views and opinions of authors expressed herein do not necessarily state or reflect those of the United States Government or any agency thereof. 


\section{DISCLAIMER}

Portions of this document may be illegible in electronic image products. Images are produced from the best available original document. 


\section{Printed in USA. Price: $\$ 1.00$ Available from the}

Office of Technical Services

U. S. Department of Commerce

Washington 25, D. C.

\section{LEGAL NOTICE}

This report was prepared as an account of Government sponsored work. Neither the United States, nor the Commission, nor any person acting on behalf of the Commission:

A. Makes any warranty or representation, expressed or implied, with respect to the accuracy, completeness, or usefulness of the information contained in this report, or that the use of any information, apparatus, method, or process disclosed in this report may not infringe privately owned rights; or

B. Assumes any liabilities with respect to the use of, or for damages resulting from the use of any information, apparatus, method, or process disclosed in this report.

As used in the above, "person acting on behalf of the Commission" includes any employee or contractor of the Commission, or employee of such contractor, to the extent that such employee or contractor of the Commission, or employee of such contractor prepares, disseminates, or provides access to, any information pursuant to his employment or contract with the Commission, or his employment with such contractor. 
ORNL-3311

UC-34 - Physics

TID.4500 (18th ed.)

Contract No. W-740 S-eng-26

ELECTRONUCLEAR DIVISION

COMPUTATION OF LOSSES DUE TO MULTIPLE SCATTERING OF

CHARGED PARTICLES IN THIN FOILS

J. B. Ball

DATE ISSUED

JAN 89963

OAK RIDGE NATIONAL LABORATORY

Oak Ridge, Tennessee

UNION CARBIDE CORPORATION

for the

U. S. ATOMIC ENERGY COMMISSION 


\section{THIS PAGE}

WAS INTENTIONALLY

LEFT BLANK 


\section{CONTENTS}

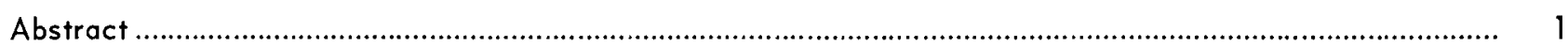

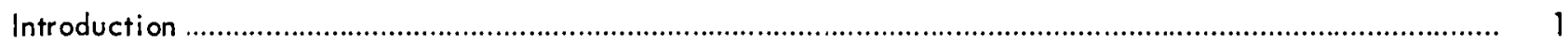

Calculation of the Root-Mean-Square Multiple-Scattering Angle ............................................................ 2

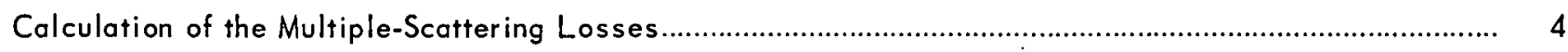

Appendix 1. Root-Mean-Square Multiple-Scattering Angle Program ............................................................. 22

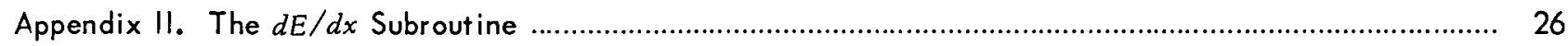

Appendix III. Program for Computing Multiple-Scattering Losses ......................................................... 28 


\title{
COMPUTATION OF LOSSES DUE TO MULTIPLE SCATTERING OF CHARGED PARTICLES IN THIN FOILS
}

\author{
J. B. Ball
}

\begin{abstract}
The losses of charged particles from a detector aperture, due to multiple scattering of the particles in thin layers of material preceding the detector, are calculated with the aid of a high-speed digital computer. The root-mean-square multiple-scattering angle is computed after the method of Moliere, and graphs are presented for protons and alpha particles scattering in nitrogen, aluminum, argon, copper, silver, and gold, and for deuterons and tritons scattering in aluminum and copper. The range of particle energy covered is from 5 to $100 \mathrm{Mev}$. A second program is used to construct a map from which losses, as a function of the root-mean-square multiple-scattering angle and the scattering configuration, may be directly read. The FORTRAN listings for both programs are given.
\end{abstract}

\section{INTRODUCTION}

In the study of nuclear reactions induced by or producing fast charged particles, it is frequently necessary to pass the charged particles through thin layers of material before or during the detection process. In passing through such foils the particle may undergo many small-angle Coulomb deflections. Under certain conditions this multiple scattering may result in enough spreading of the particle trajectories to affect the experimental results. The careful design of an experiment often requires an estimate to be made of the effects of multiple scattering.

Since these small-angle Coulomb deflections are randomly oriented, the first-order distribution of the scattering should follow a normal, or Gaussian, distribution:

$$
P(\theta) d \theta=\left(2 \theta / \theta_{\mathrm{av}}^{2}\right) \exp \left(-0^{2} / \theta_{\mathrm{av}}^{2}\right) d \theta \text {. }
$$

where $P(\theta)$ is the probability for scattering into an angular increment $d \theta$ about a spatial angle $\theta$ measured with respect to the axis of the unscattered particles, and $\theta_{a v}$ is the root-mean-square angle of the multiple scattering. The distribution is normalized to unity over all space.

Since, in general, both the area of the scattering foil and of the detector must be considered of finite size, each point on the surface of the scatterer will give rise to a two-dimensional Gaussian distribution of multiply scattered particles. The sum of these two-dimensional Gaussians is then incident on the plane containing the detector aperture.

The calculation of multiple-scattering losses thus requires two distinct steps: (1) the computation of the root-mean-square multiple-scattering angle, which characterizes the multiple-scattering distribution, and (2) the calculation of the fraction of all these distributions, arising from the scatterer surface, 
falling outside the detector aperture. While the first of these is relatively easy to compute, the second requires a long and tedious numerical integration over the two-dimensional Gaussians. Dickinson and Dodder ${ }^{1}$ have presented a graphical method of performing this integration by constructing a two-dimensional Gaussian graph and counting appropriate area increments. This reduces the required time of solution to about half an hour. They have also calculated the losses for a few representative cases, but the interpolation or extrapolation of these values to match a given experimental situation generally involves sufficient uncertainty to make a specific graphical integration necessary.

In this work, advantage of the fast computing capabilities of the IBM 7090 is made in computing enough cases to allow the mapping of a multiple-scattering-loss surface, so that the loss from any given experimental situation may be read directly. 'Ihe computer is also used to calculate the rootmean-square multiple-scattering angle $\theta_{\mathrm{av}}$ as a function of foil thickness for a number of different particles, at energies between 5 and $100 \mathrm{Mev}$, scattering from nitrogen, argon, aluminum, copper, silver, and gold.

\section{CALCULATION OF THE ROOT-MEAN.SQUARE MULTIPLE-SCATTERING ANGLE}

The first analytical treatment of multiple scattering was given by $\mathbb{W}$ illiams. ${ }^{2}$ He considered the scattering as following the Gaussian distribution given by Eq. (1). The root-mean-square multiplescattering angle needed to establish the width of the distribution was then calculated from the relationship

$$
\theta_{\mathrm{av}}^{2}=x_{c}^{2} \ln \left(\theta_{1} / \theta_{2}\right)
$$

where $\chi_{c}$ is an angular unit, and the logarithm term is a measure of the mean number of scatterings. In the logarithm term, $\theta_{1}$ is the angle beyond which a particle traversing the foil suffers, on the average, only one collision, and $\theta_{2}$ is the angle below which no Coulomb scattering occurs due to the shielding of the nuclear charge by the orbital electrons. Williams has solved for $\theta_{2}$ in the classical case, valid when $\gamma \gg 1$, and with the Born approximation, valid for $\gamma<<1$. Here $\gamma=Z z / 137 \beta$, where $z$ is the charge on the particle, $Z$ is the nuclear charge of the scatterer, and $\beta=v / c$ for the particle. Neither of these methods is valid near $\gamma=1$, and the results of the two methods do not extrapolate through this region. Since the condition $\gamma=1$ occurs, for example, for protons of $22 \mathrm{Mev}$ on copper, or alphas of $28 \mathrm{Mev}$ on aluminum, this singularity in the simple theory occurs in the region of interest for this paper.

\footnotetext{
${ }_{W}$. C. Dickinson and D. C. Dodder, Rev. Sci. Instr. 24, 428 (1993).

${ }^{2}$ E. J. Williams, Revs. Modem Phys. 17, 217 (1949); Proc. Roy. Soc. (London) A 169, 531 (1939).
} 
A more complete theory of multiple scattering has been developed by Moliere. ${ }^{3}$ An expression for the minimum scattering angle was developed quantum mechanically that is valid for all values of $\gamma$. In Moliere's theory, the root-mean-square multiple-scattering angle $\theta_{a v}$ is calculated from the expression

$$
\theta_{\mathrm{av}}^{2}=B X_{c}^{2}
$$

where $\chi_{c}$ is the same angular unit used in Eq. (2).

Moliere also treats the multiple-scattering distribution in more detail. He represents the probability distribution with the series

$$
P(\theta) d \theta=\left(\frac{\theta}{\theta_{\mathrm{av}}^{2}}\right)\left[2 \exp \left(-\theta_{\mathrm{av}}^{2}\right)+\frac{1}{B} f^{1}(\theta)+\frac{1}{B^{2}} f^{2}(\theta)+\ldots\right] d \theta .
$$

The first term in the series is just the Gaussian distribution of Eq. (1). The second term in the series represents the contribution to the distribution from large-angle single scatterings. The third term represents the contribution from large-angle double scatterings, etc.

The mean number $\Omega_{b}$ of scatterings in the Moliere theory is given by the equation

$$
\log \Omega_{b}=5.215+\log \left[t \gamma^{2} z^{\left.-2 / 3 / A\left(1.13+3.76 \gamma^{2}\right)\right]},\right.
$$

where $t$ is the scatterer thickness in $\mathrm{mg} / \mathrm{cm}^{2}$, and $Z$ and $A$ are the atomic number and atomic weight, in atomic mass units, of the scatterer respectively. Instead of using $\Omega_{b}$ to determine the width of the Gaussian, Moliere defines the quantity $B$ which is slightly greater than $\Omega_{b}$ and allows the first term of Eq. (4) to yield a more accurate approximation to the total distribution. The quantity $B$ is related to $\Omega_{b}$ by the equation

$$
e^{B} / B=\Omega_{b} / 1.167 .
$$

In this work the spatial distribution of the multiple scattering will be approximated by the first term of Eq. (4), that is, Eq. (1), and the root-mean-square scattering angle $\theta_{\mathrm{av}}$ will be computed from Eq. (3), with $B$ defined in Eq. (6) and $\chi_{c}^{2}$ given by the equation

$$
X_{c}^{2}=4 \pi N t z^{2} Z^{2} e^{4} /(p v)^{2}
$$

where $N$ is the number of atoms per milligram of scatterer, $t$ is the scatterer thickness in $\mathrm{mg} / \mathrm{cm}^{2}, z$ is the charge of the scattered particle, $Z$ is the atomic number of the scatterer material, $p=m v / \sqrt{1-\beta^{2}}$ for the particle, and $e$ is the electron charge.

The approximation of using only the first term in Eq. (4) to represent the probability distribution may introduce errors up to $10 \%$ (ref 1 ). Nigam et al. ${ }^{4}$ have pointed out that certain assumptions made by Moliere have introduced errors in the expression for the minimum scattering angle that affect the higherorder terms of the distribution. This difference does not seem to be important for this paper, where only

\footnotetext{
${ }^{3}$ G. Moliere, Z. Naturforsch. 3a, 78 (1948) (also available as AEC-tr-2119 and AERE Lib/Trans 626).

${ }^{4}$ B. P. Nigam, M. K. Sundaresan, and Ta-You Wu, Phys. Rev. 115, 491 (1959).
} 
the Gaussian term is considered. The values of $\theta_{\text {av }}$ calculated for protons and alpha particles scattering in nitrogen, aluminum, argon, copper, silver, and gold over an energy range 5 to $100 \mathrm{Mev}$ are shown in Figs. 1-12. The program used to compute $\theta_{\text {av }}$ is described in more detail in Appendix I; a FORTRAN listing is also given.

In the simple theory of Williams, ${ }^{2}$ the root-mean-square scattering angle $\theta_{\text {av }}$ depends only on the charge and not on the mass of the particle. This is not true in the case of the Moliere treatment, and the values of $\theta_{\mathrm{av}}$ for protons, deuterons, and tritons deviate somewhat from each other. The values of $\theta_{\text {av }}$ calculated for deuterons and tritons in aluminum and copper are shown in Figs. 13-16. The deviations become smaller as the scatterer $Z$ is increased. It is interesting to note that the spacing of the energies in these figures is approximately logarithmic. This makes it convenient to use a logarithmic scale for interpolating between energies.

\section{CALCULATION OF THE MULTIPLE.SCATTERING LOSSES}

The geometry considered in these calculations is shown in Fig. 17. Almost all the experimental configurations encountered can be treated in this geometry. The notation used is that of Dickinson and Dodder. ${ }^{1}$

Since the angles entering into the computation are never very large, it is convenient to make the approximation $\tan \theta \cong \theta$. The value of the root-mean-square displacement then becomes

$$
\rho_{\mathrm{av}}=\theta_{\mathrm{av}} D
$$

and the distribution of Eq. (1) becomes

$$
P(\rho) d \rho=2 \rho / \rho_{\mathrm{av}}^{2} \exp \left(-\rho^{2} / \rho_{\mathrm{av}}^{2}\right) d \rho .
$$

Since the unit area in the plane containing $\rho$. is given by

$$
d A=2 \pi \rho d \rho,
$$

the probability per unit area on the detector surface will be

$$
P(\rho)=\left(\pi \rho_{\mathrm{av}}^{2}\right)^{-1} \exp \left(-\rho^{2} / \rho_{\mathrm{av}}^{2}\right) .
$$

By using Eq. (11) to compute the probability for scattering into a given area of the detector surface from a given area of the scatterer surface and taking appropriate sums over both surfaces, the loss of particles may be computed for any combination of $R_{1} / \rho_{\text {av }}$. A map of the multiple-scattering losses computed in this fashion is shown in Fig. 18. The terms $R_{1}$ and $R_{2}$ are the detector and scatterer radii in either order, since the geometry of the scattering is symmetrical about the midplane. The multiple-scattering loss computation is discussed in more detail in Appendix III; the FORTRAN listing for the program is also given.

Estimation of the multiple-scattering losses with Fig. 18 requires the following steps. The value of $\theta_{\mathrm{av}}$ is estimated from one of the graphs in the preceding section. The value of $\rho_{\mathrm{av}}$ is computed from Eq. (8). The values of $R_{1} / \rho_{\mathrm{av}}$ and $R_{2} / \rho_{\mathrm{av}}$ are then computed, and the loss corresponding to these values is read from Fig. 18. 


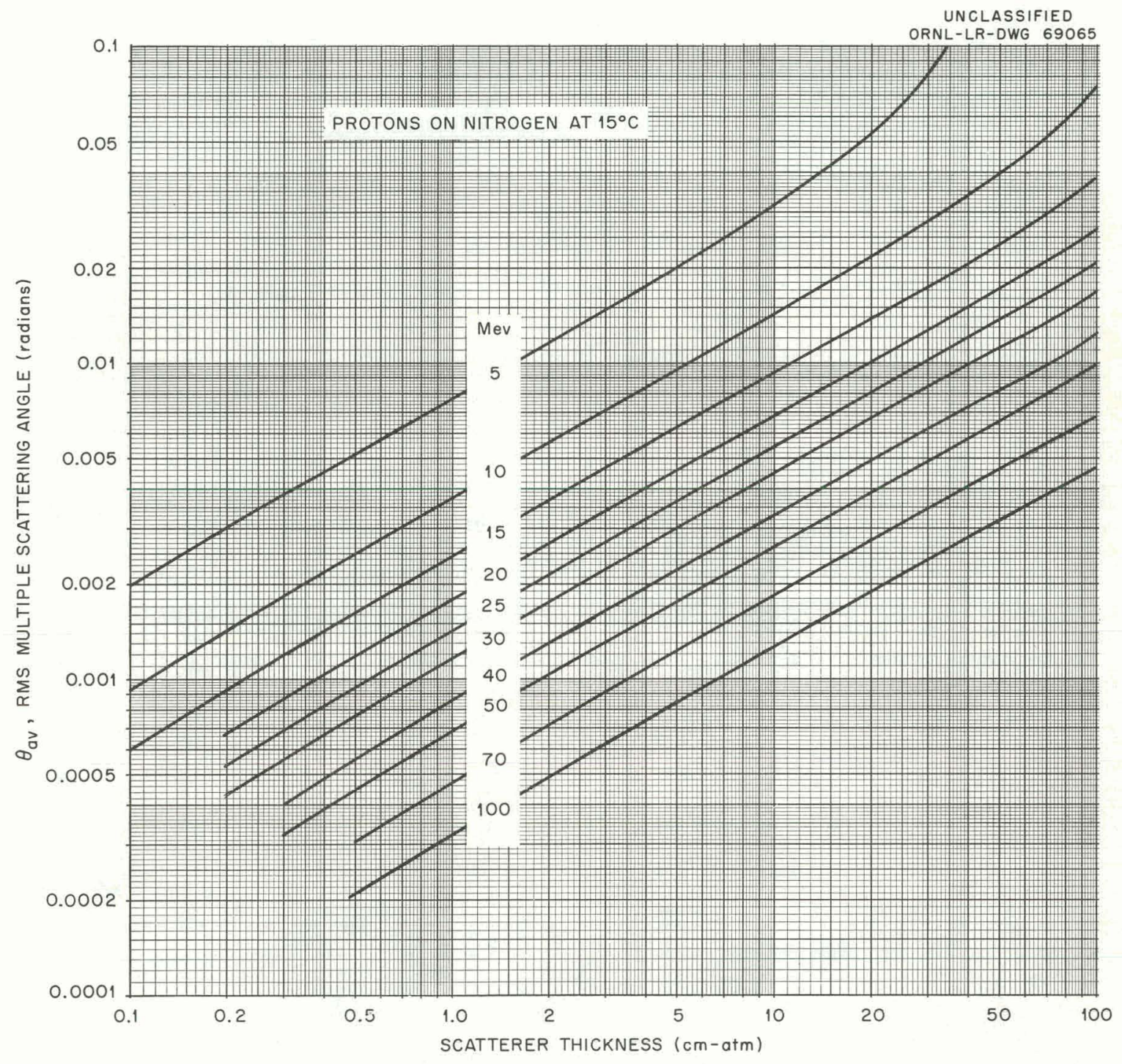

Fig. 1. Root-Mean-Square Multiple-Scattering Angle, as a Function of Incident Particle Energy and Scatterer Thickness, for Protons on Nitrogen. 


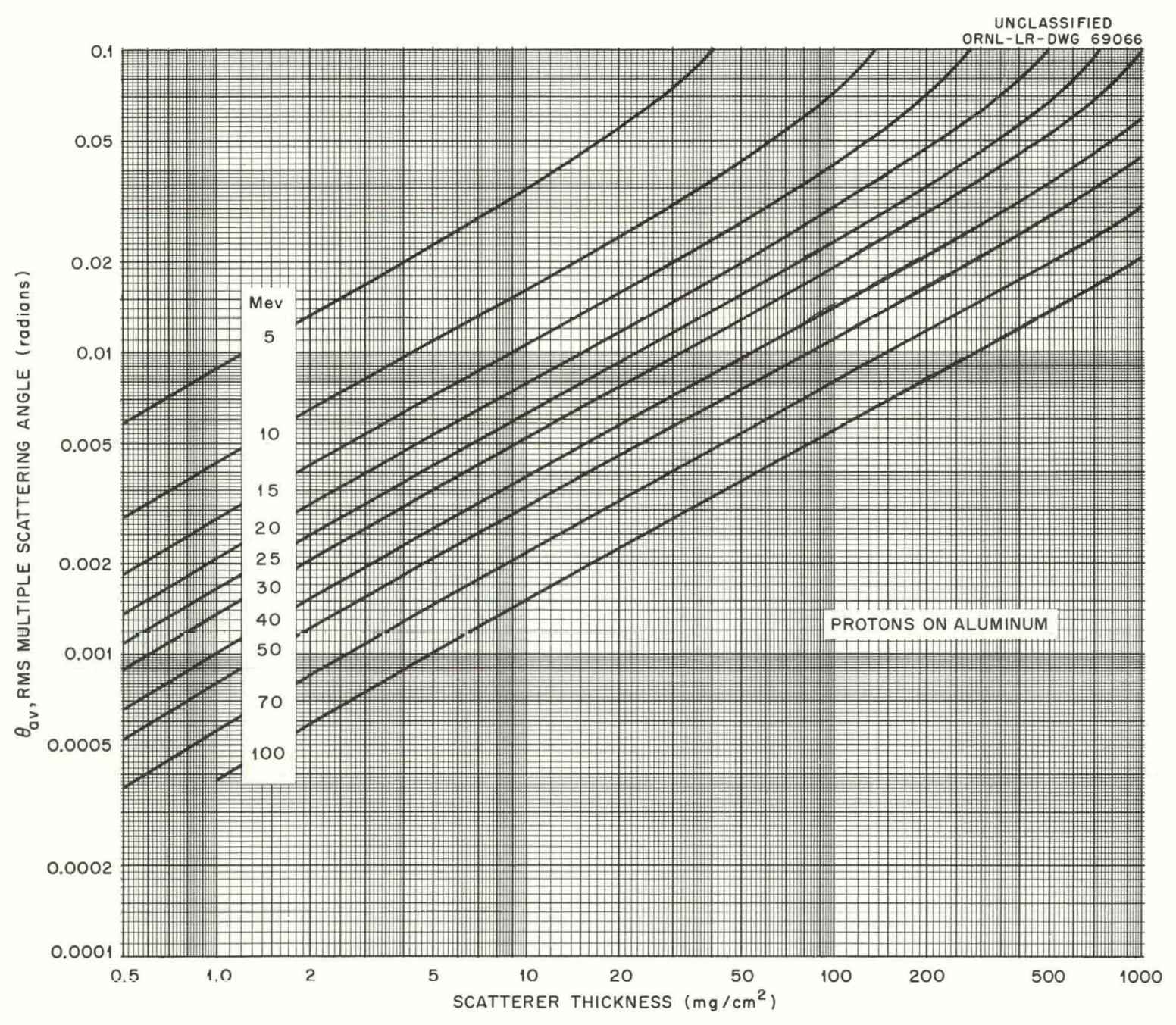

Fig. 2. Root-Mean-Square Multiple-Scattering Angle, as a Function of Incident Particle Energy and Scatterer Thickness, for Protons on Aluminum. 


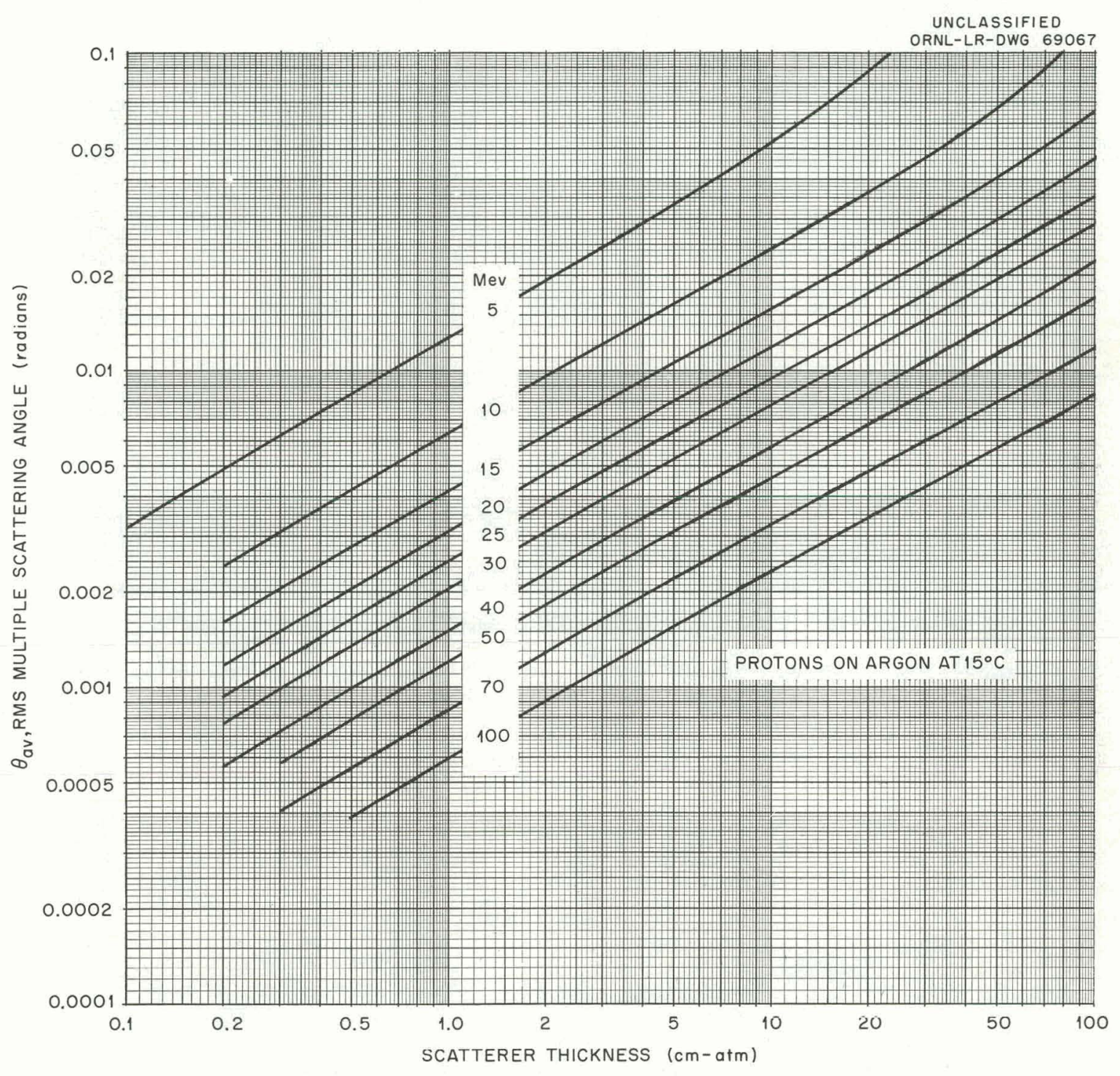

Fig. 3. Root-Mean-Square Multiple-Scattering Angle, as a Function of Incident Particle Energy and Scatterer Thickness, for Protons on Argon. 


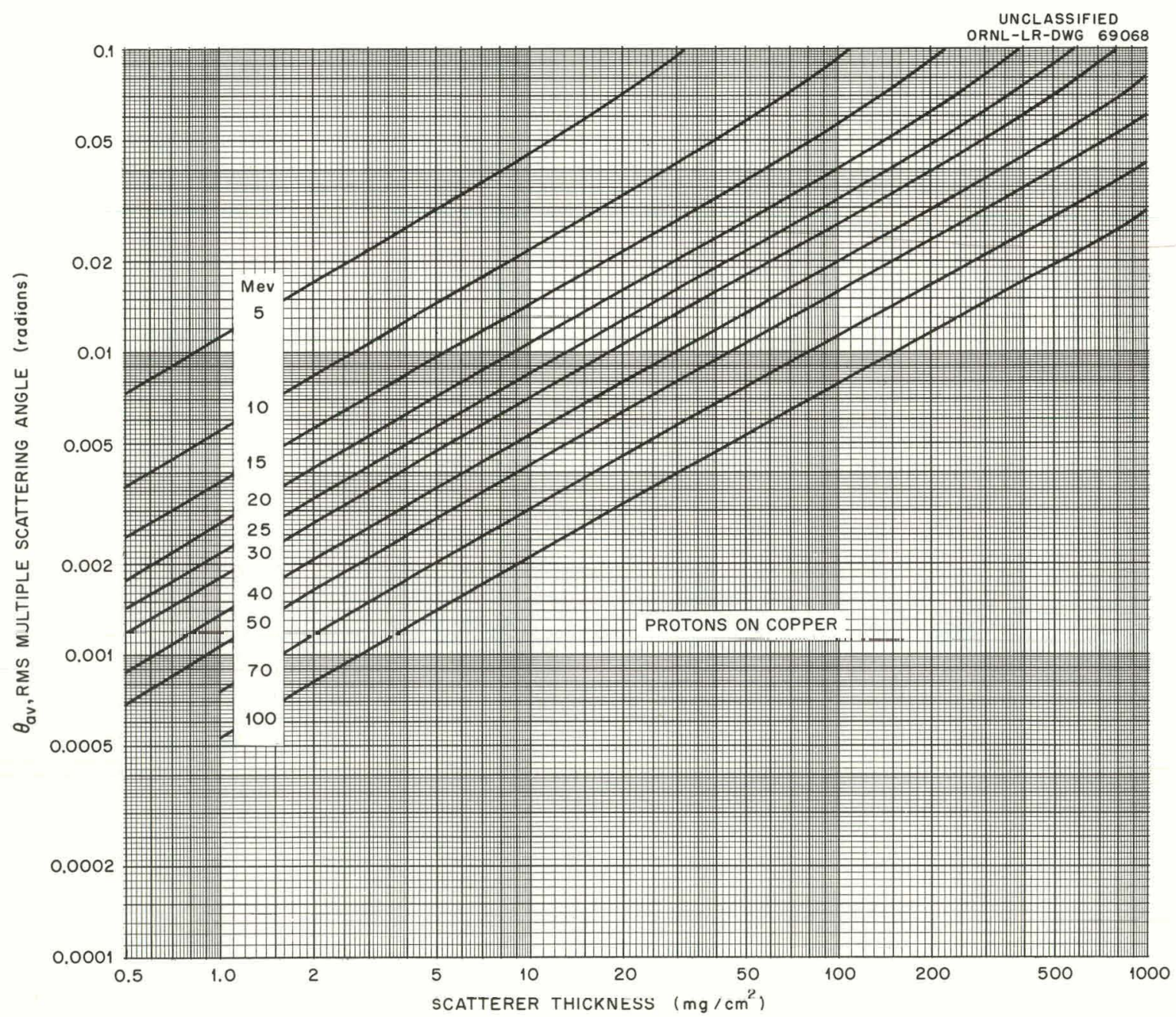

Fig. 4. Root-Mean-Square Multiple-Scattering Angle, as a Function of Incident Particle Energy and Scatterer Thickness, for Protons on Copper. 


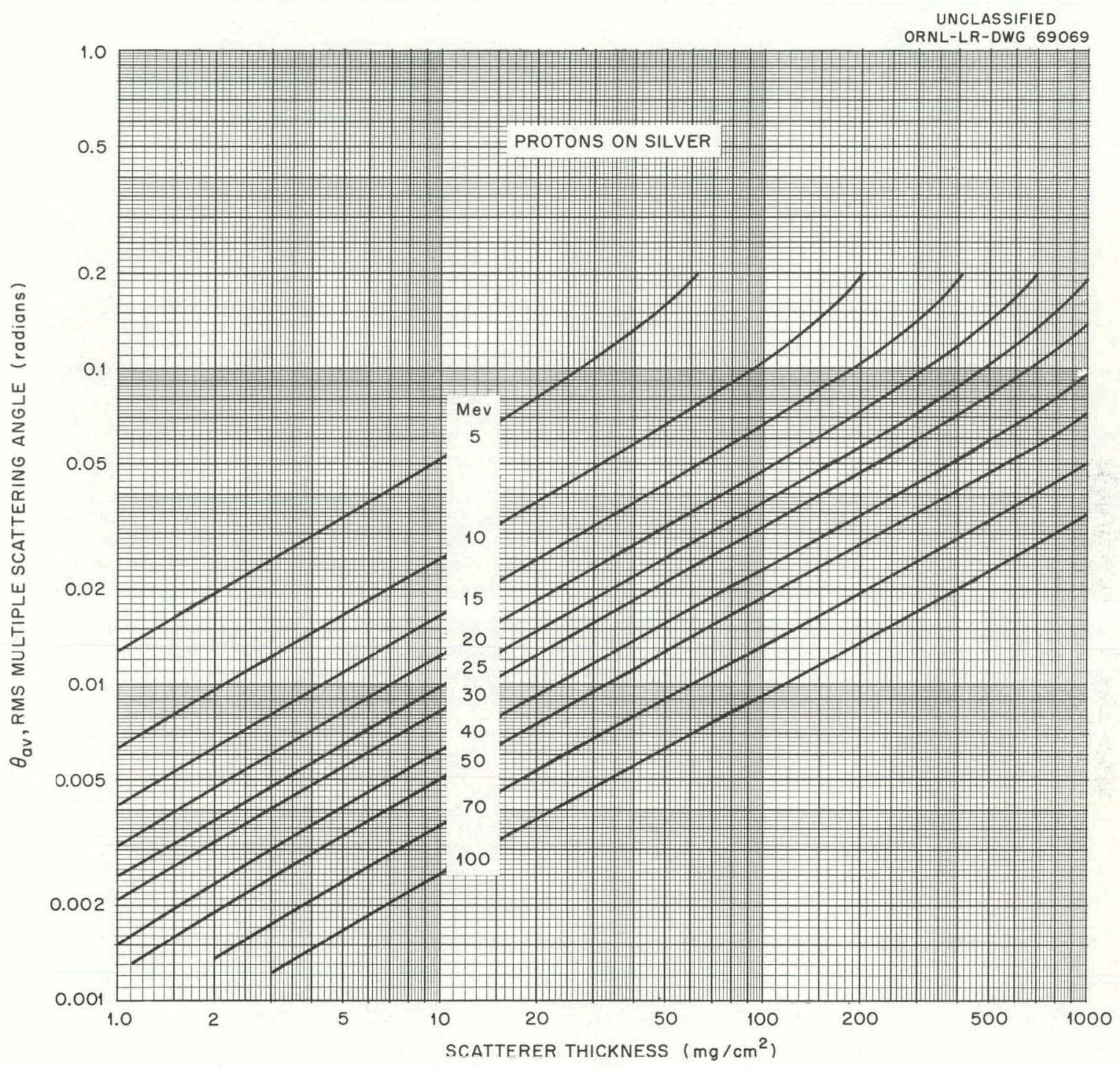

Fig. 5. Root-Mean-Square Multiple-Scattering Angle, as a Function of Incident Particle Energy and Scatterer Thickness, for Protons on Silver. 


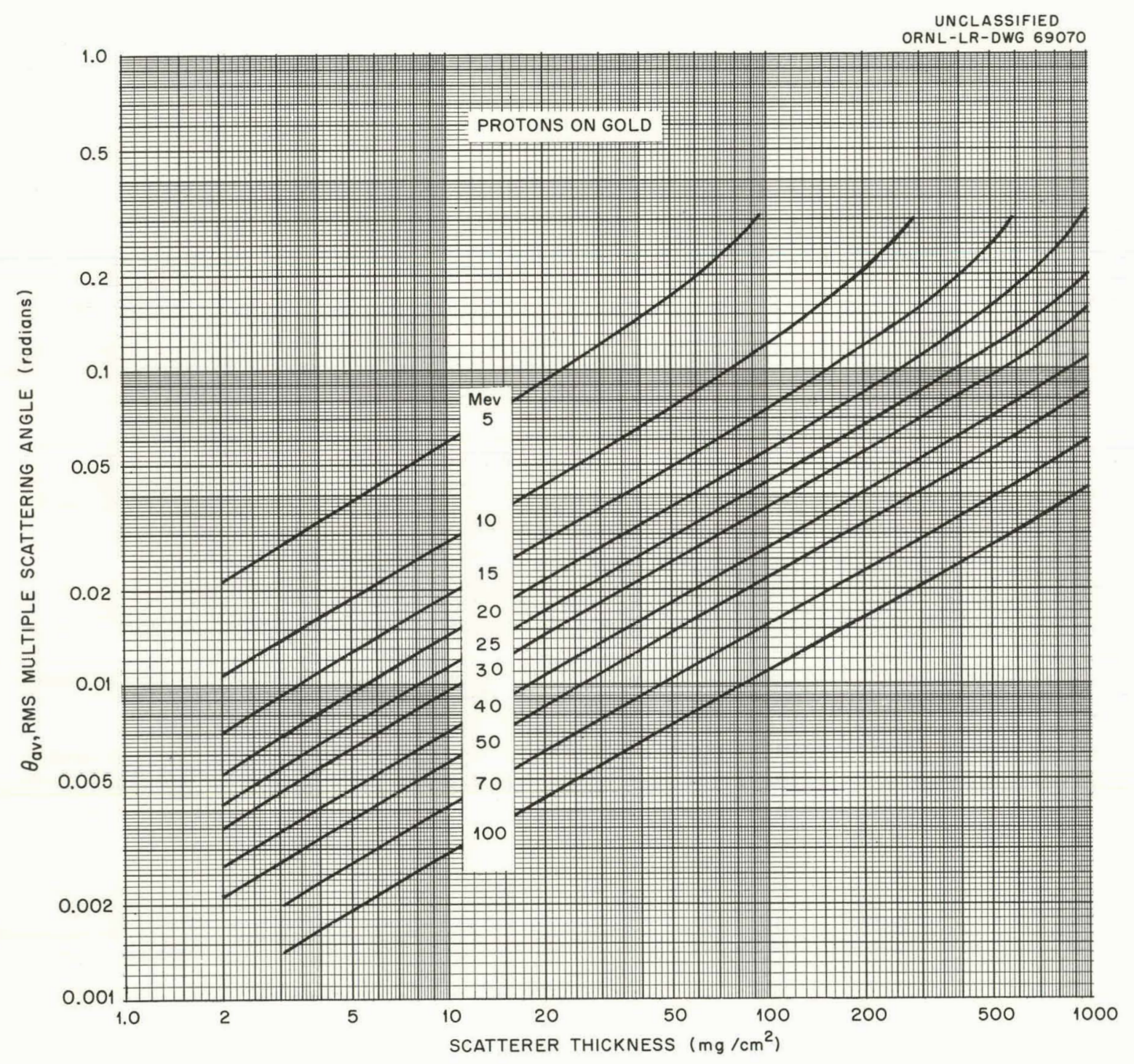

Fig. 6. Root-Mean-Square Multiple-Scattering Angle, as a Function of Incident Particle Energy and Scatterer Thickness, for Protons on Gold. 


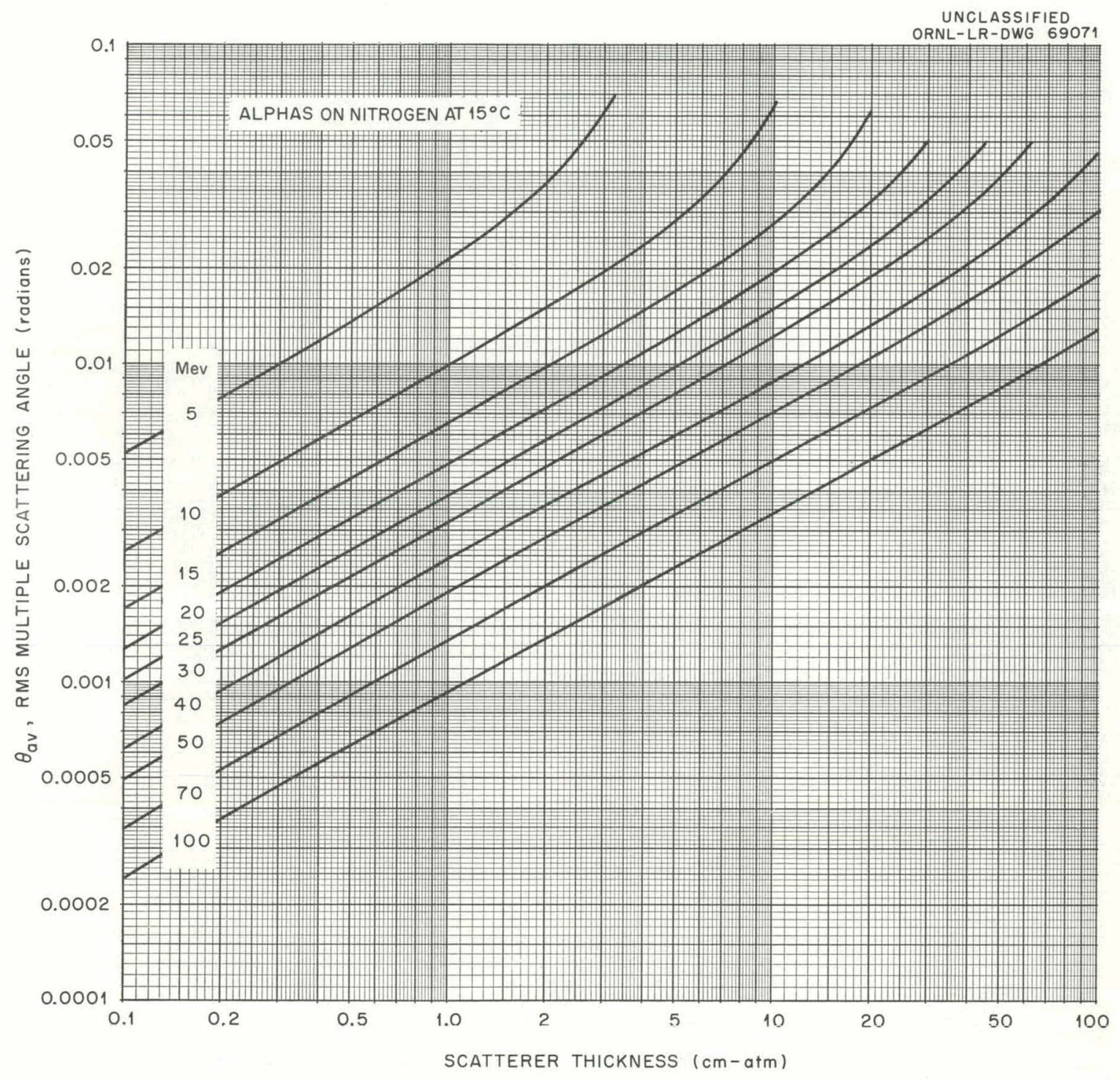

Fig. 7. Root-Mean-Square Multiple-Scattering Angle, as a Function of Incident Particle Energy and Scatterer Thickness, for Alpha Particles on Nitrogen. 


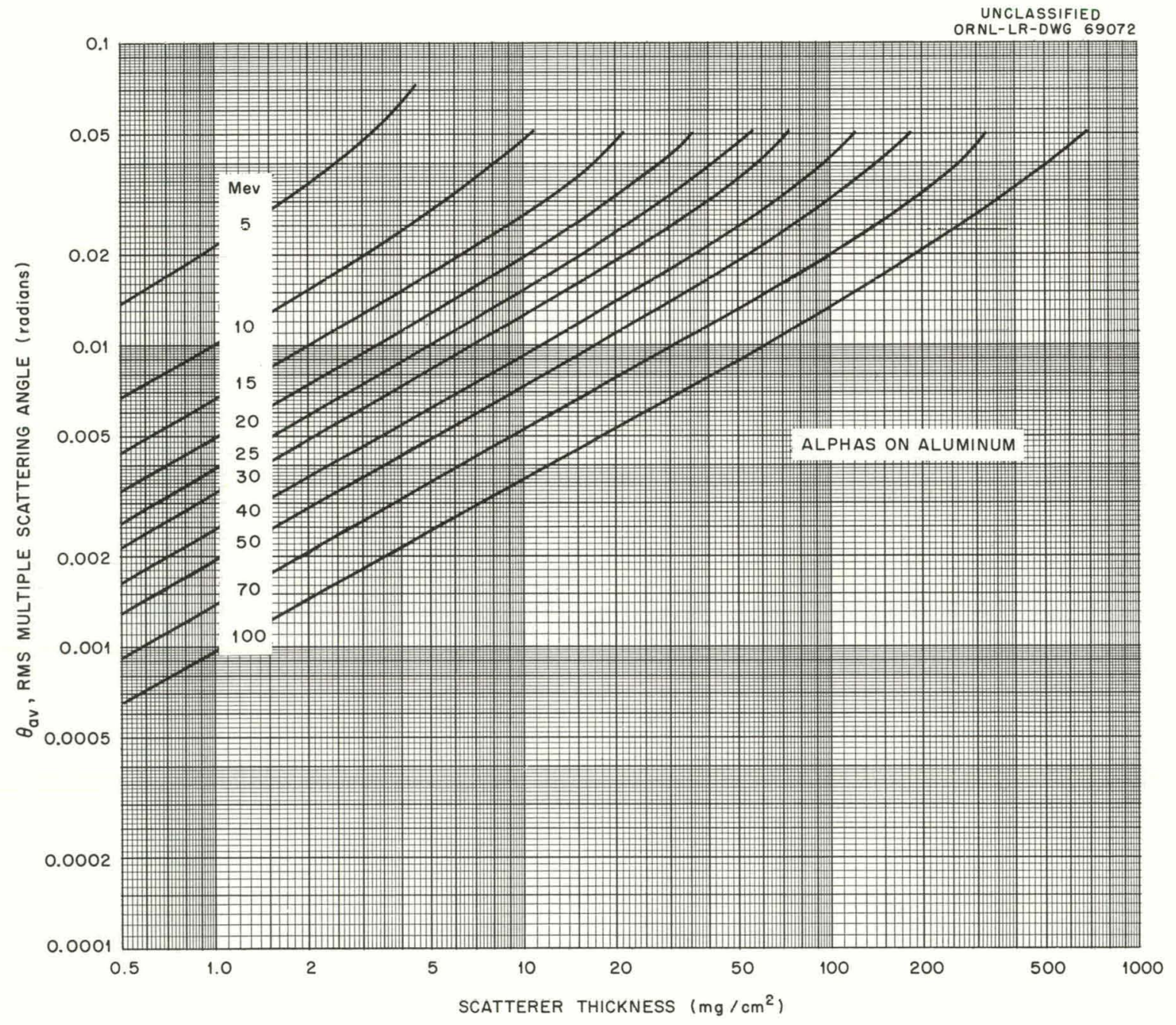

Fig. 8. Root-Mean-Square Multiple-Scattering Angle, as a Function of Incident Particle Energy and Scatterer Thickness, for Alpha Particles on Aluminum. 


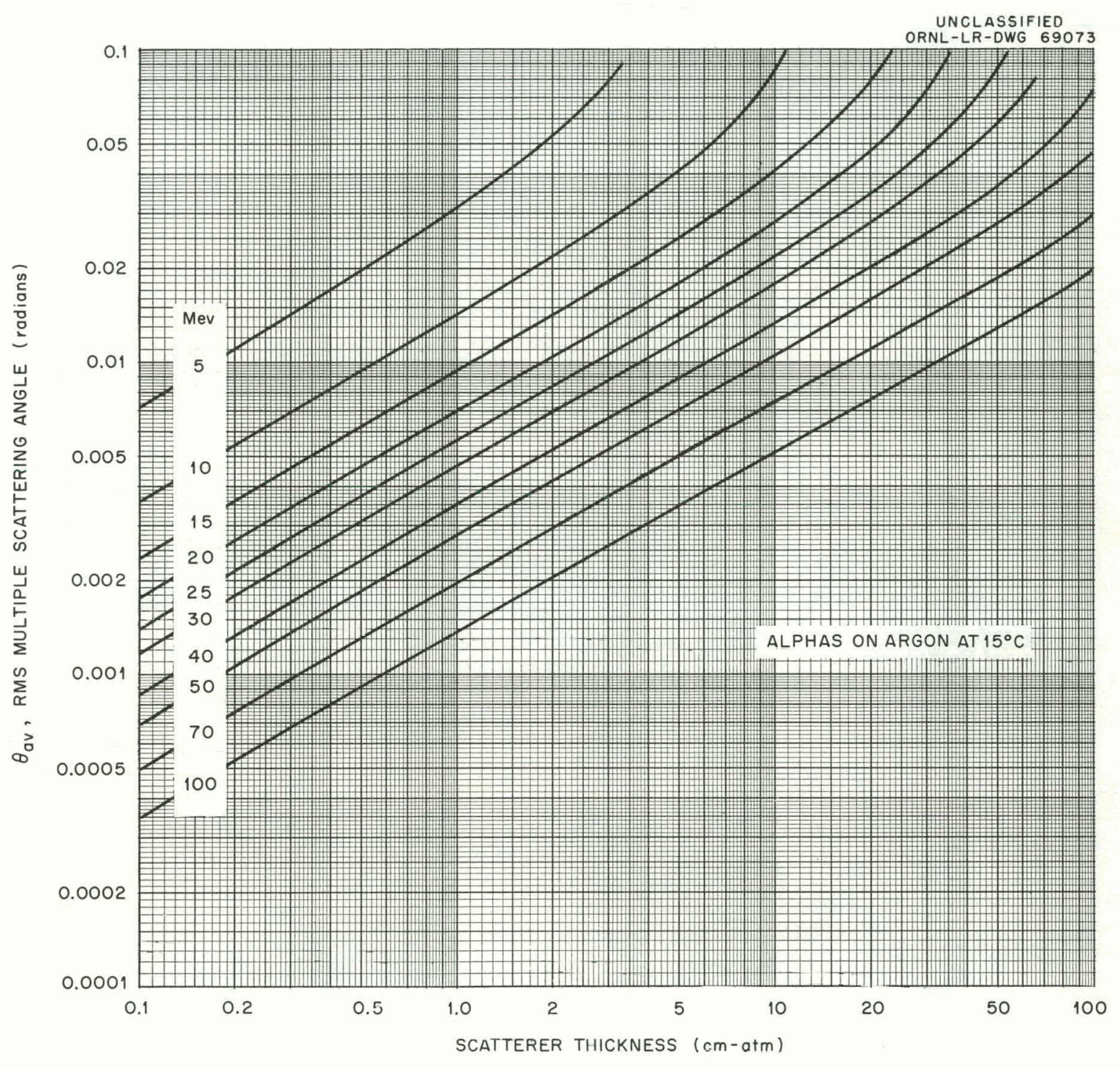

Fig. 9. Root-Mean-Square Multiple-Scattering Angle, as a Function of Incident Particle Energy and Scatterer Thickness, for Alpha Particles on Argon. 


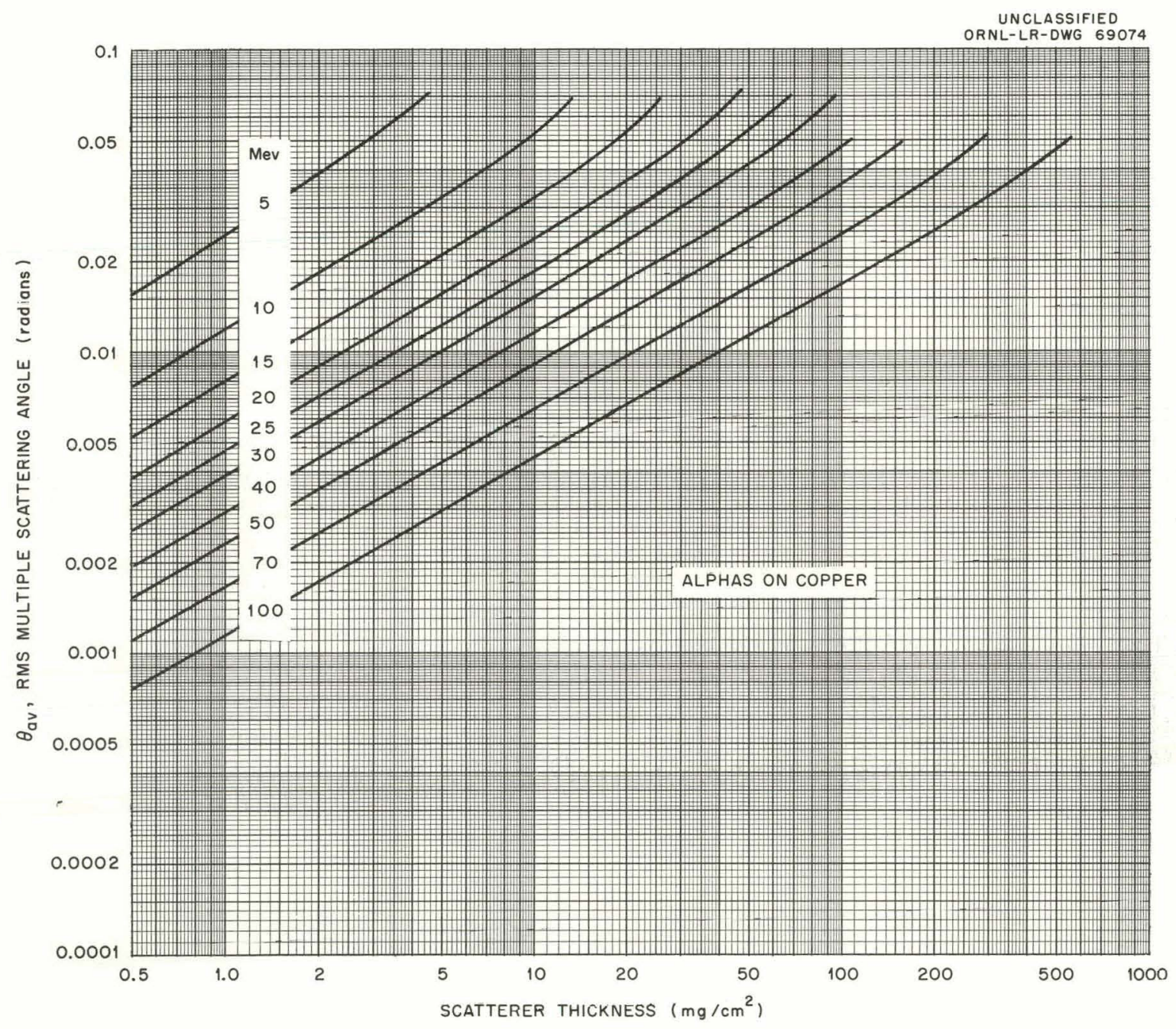

Fig. 10. Root-Mean-Square Multiple-Scattering Angle, as a Function of Incident Particle Energy and Scatterer Thickness, for Alpha Particles on Copper. 


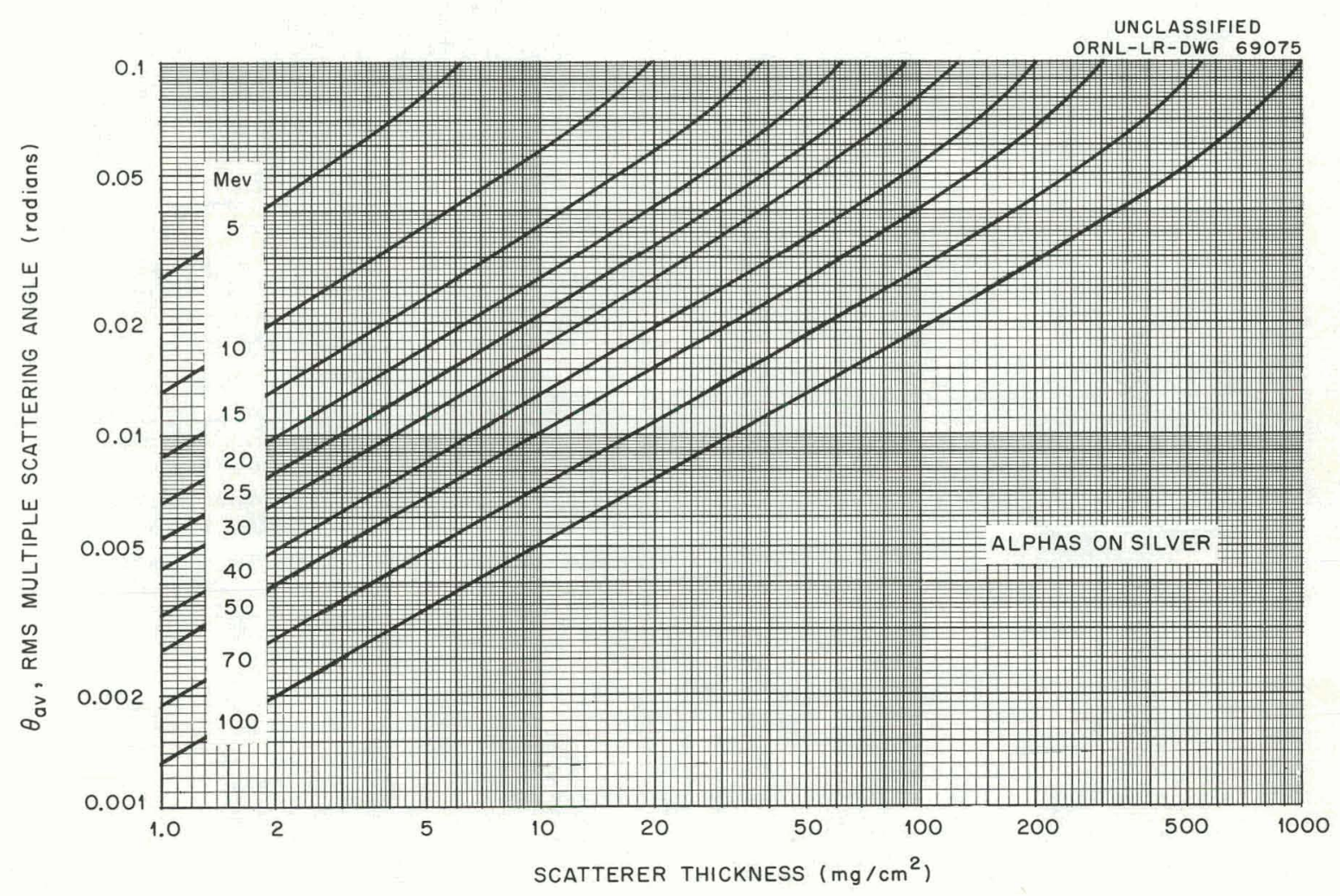

Fig. 11. Root-Mean-Square Multiple-Scattering Angle, as a Function of Incident Particle Energy and Scatterer Thickness, for Alpha Particles on Silver. 


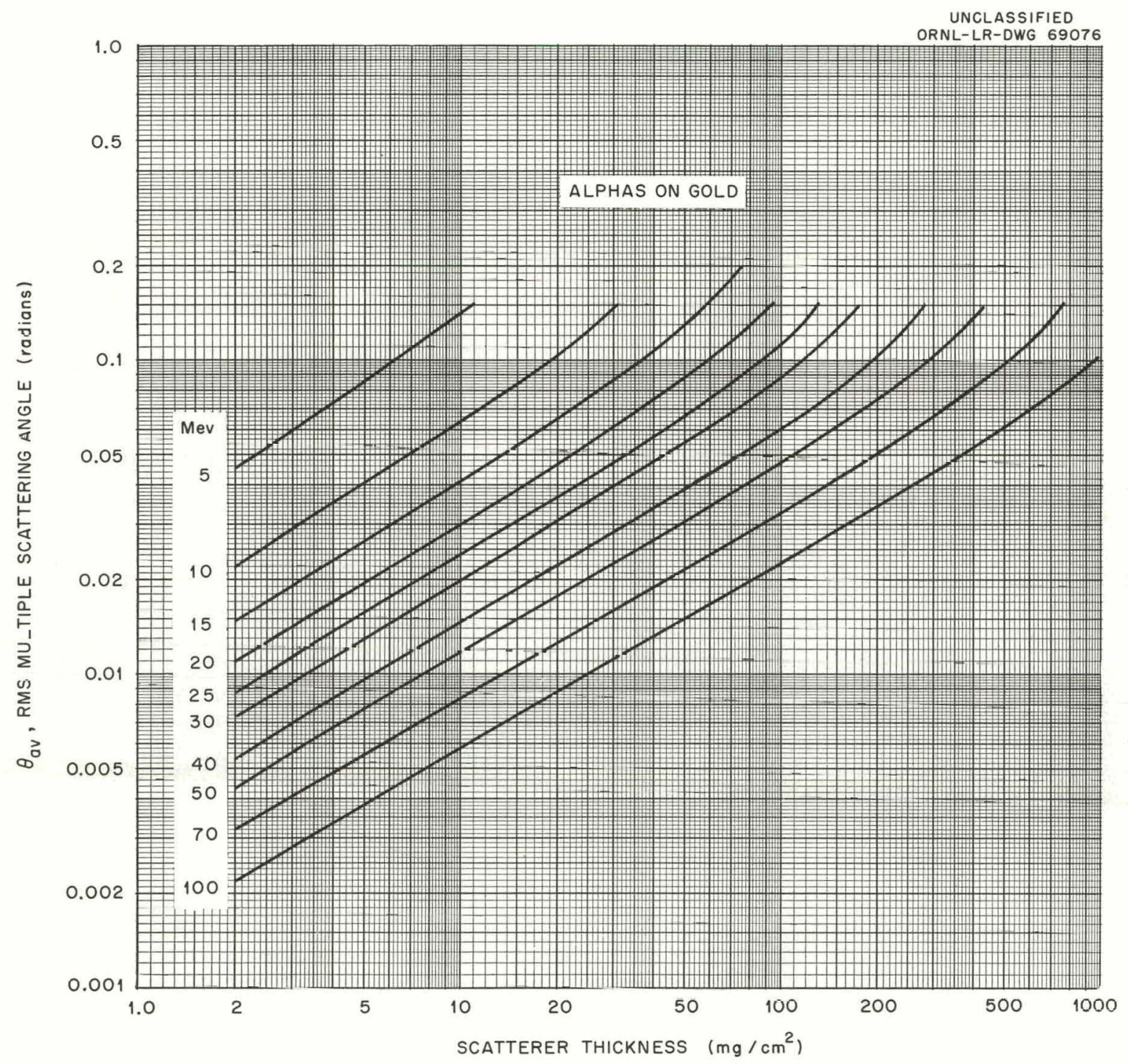

Fig. 12. Root-Mean-Square Multiple-Scattering Angle, as a Function of Incident Particle Energy and Scatterer Thickness, for Alpha Particles on Gold. 


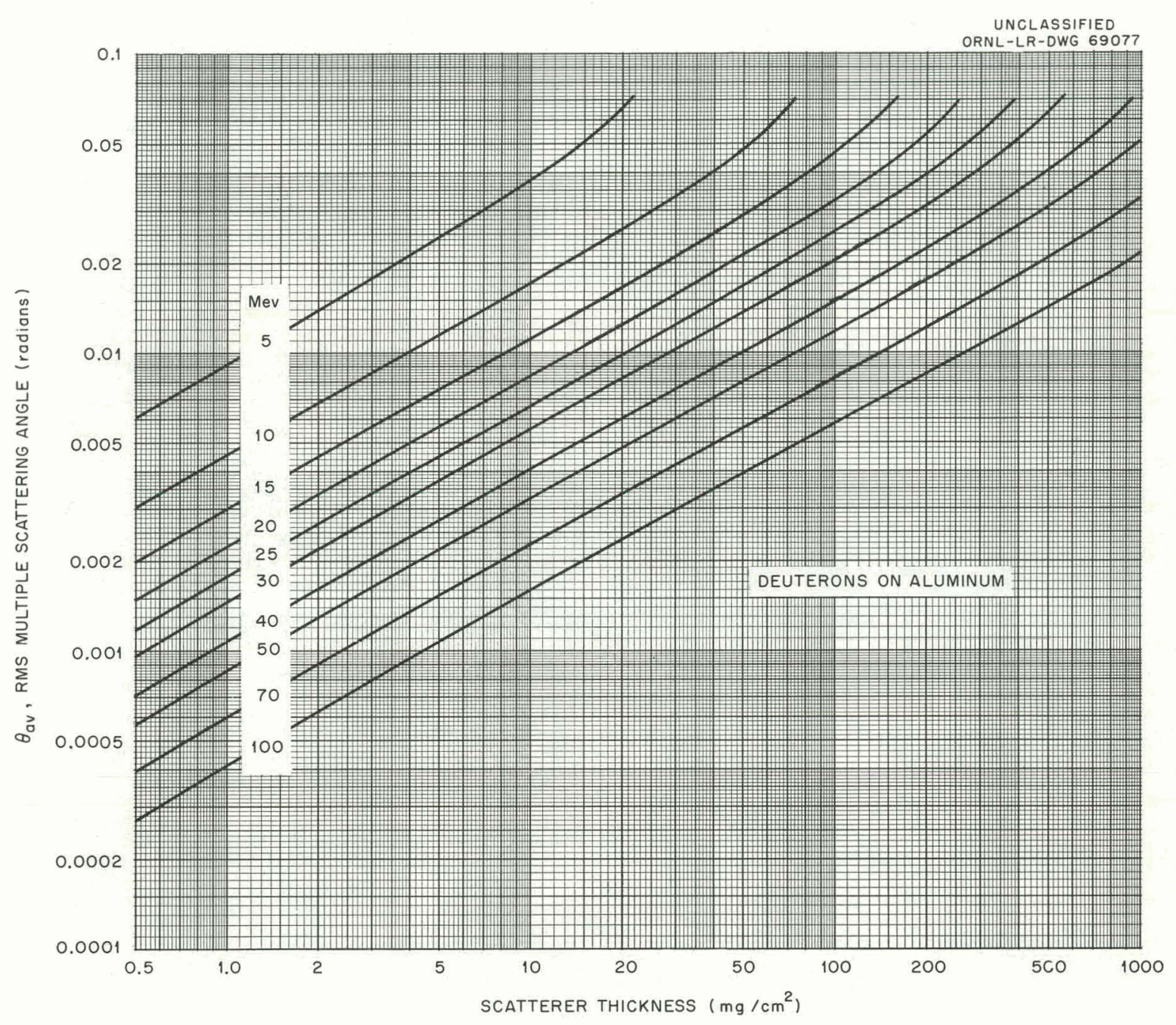

Fig. 13. Root-Mean-Square Multiple-Scattering Angle, as a Function of Incident Particle Energy and Seatterer Thickness, for Deuterons on Aluminum. 


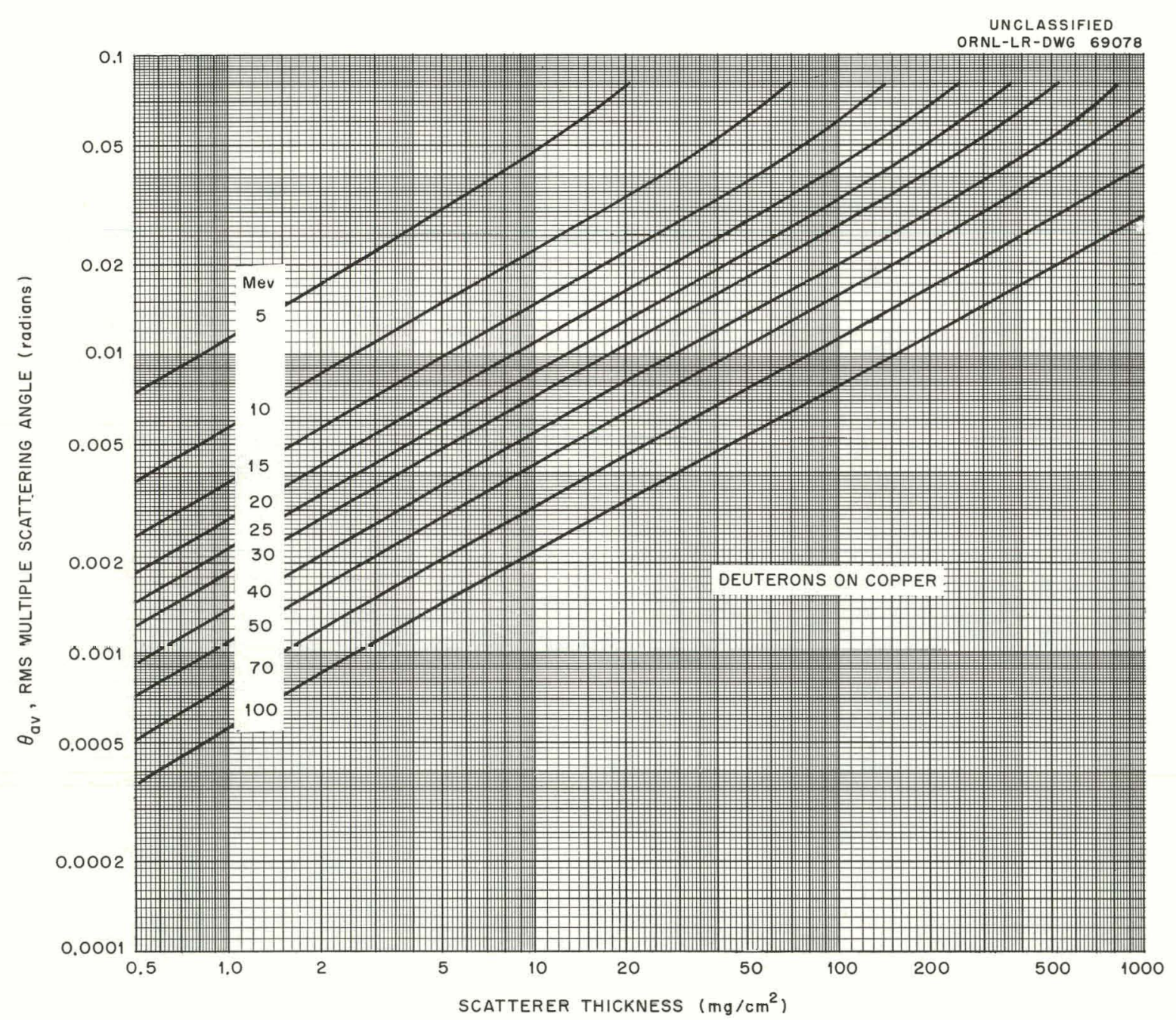

Fig. 14. Root-Mean-Square Multiple-Scattering Angle, as a Function of Incident Particle Energy and Scatterer Thickness, for Deuterons on Copper. 


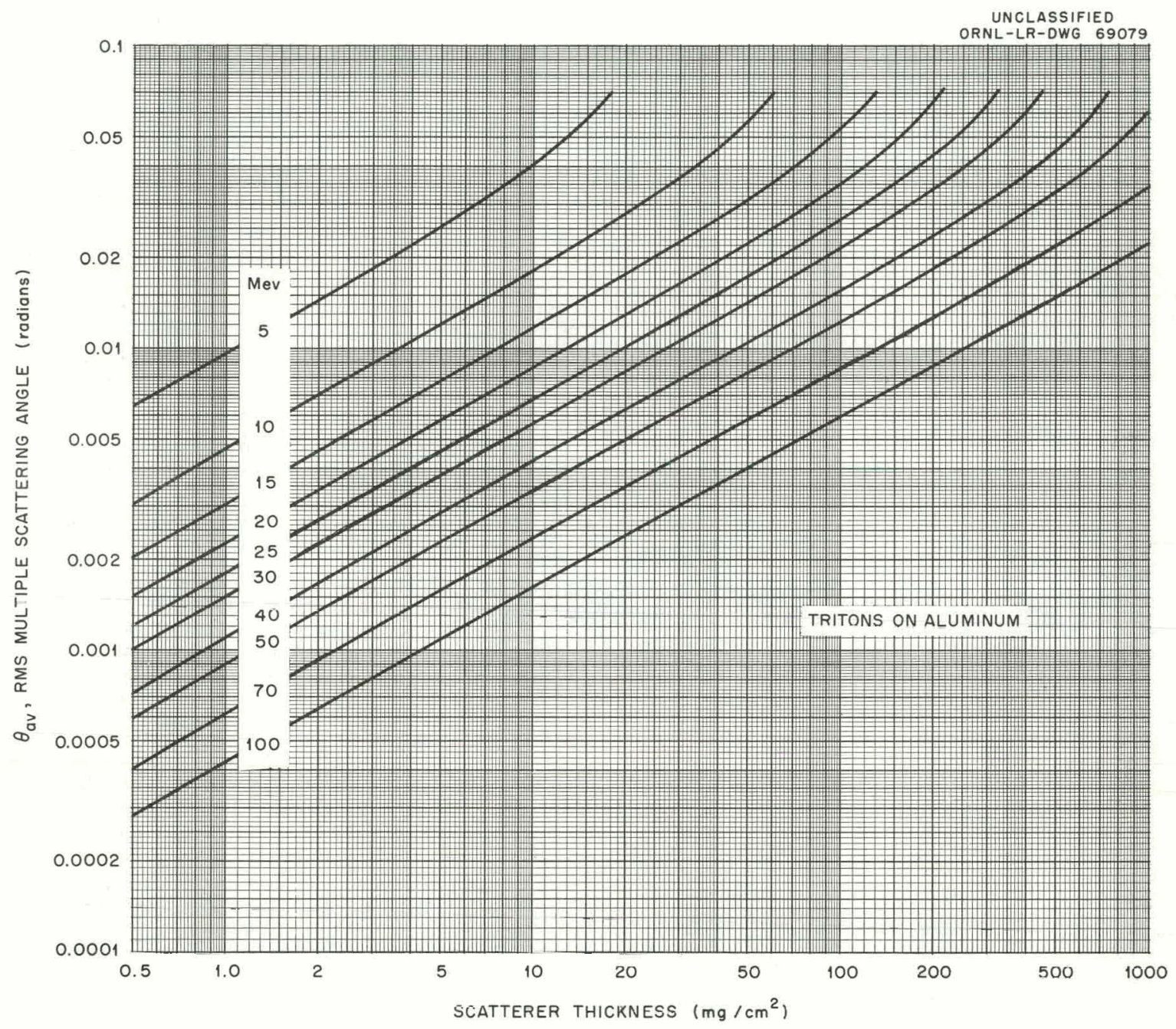

Fig. 15. Root-Mean-Square Multiple-Scattering Angle, as a Function of Incident Particle Energy and Scatterer Thickness, for Tritons on Aluminum. 


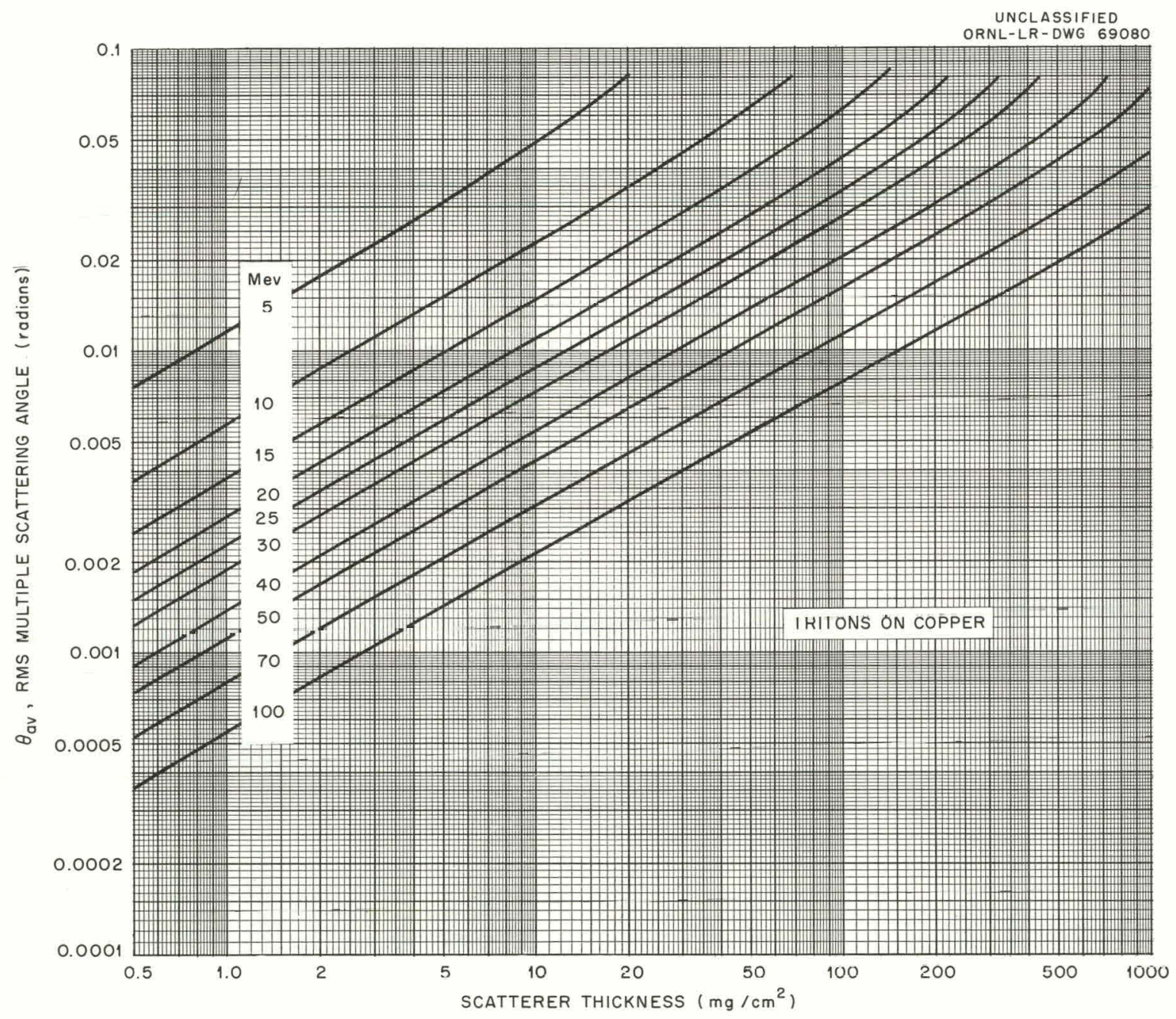

Fig. 16. Root-Mean-Square Multiple-Scattering Angle, as a Function of Incident Particle Energy and Scatterer Thickness, for Tritons on Copper. 


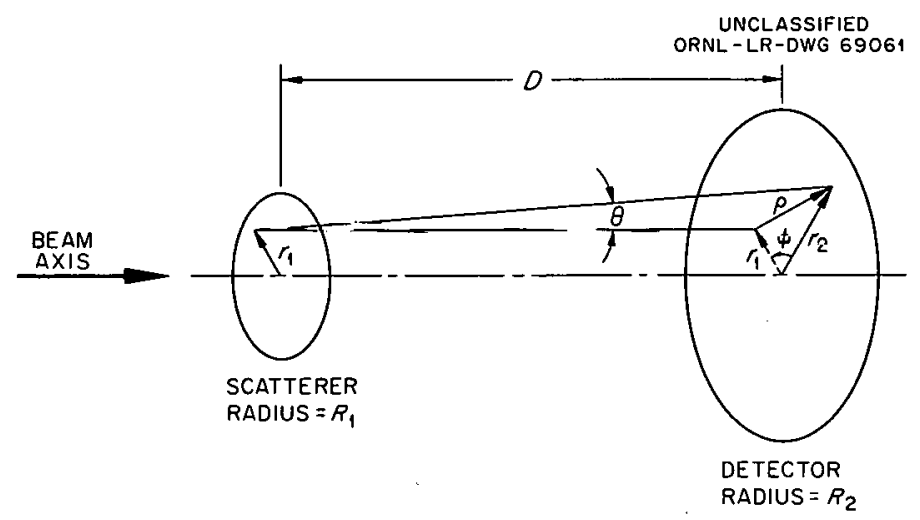

Гiy: 17. Soattaring Snnfiguration Considered in This Work.

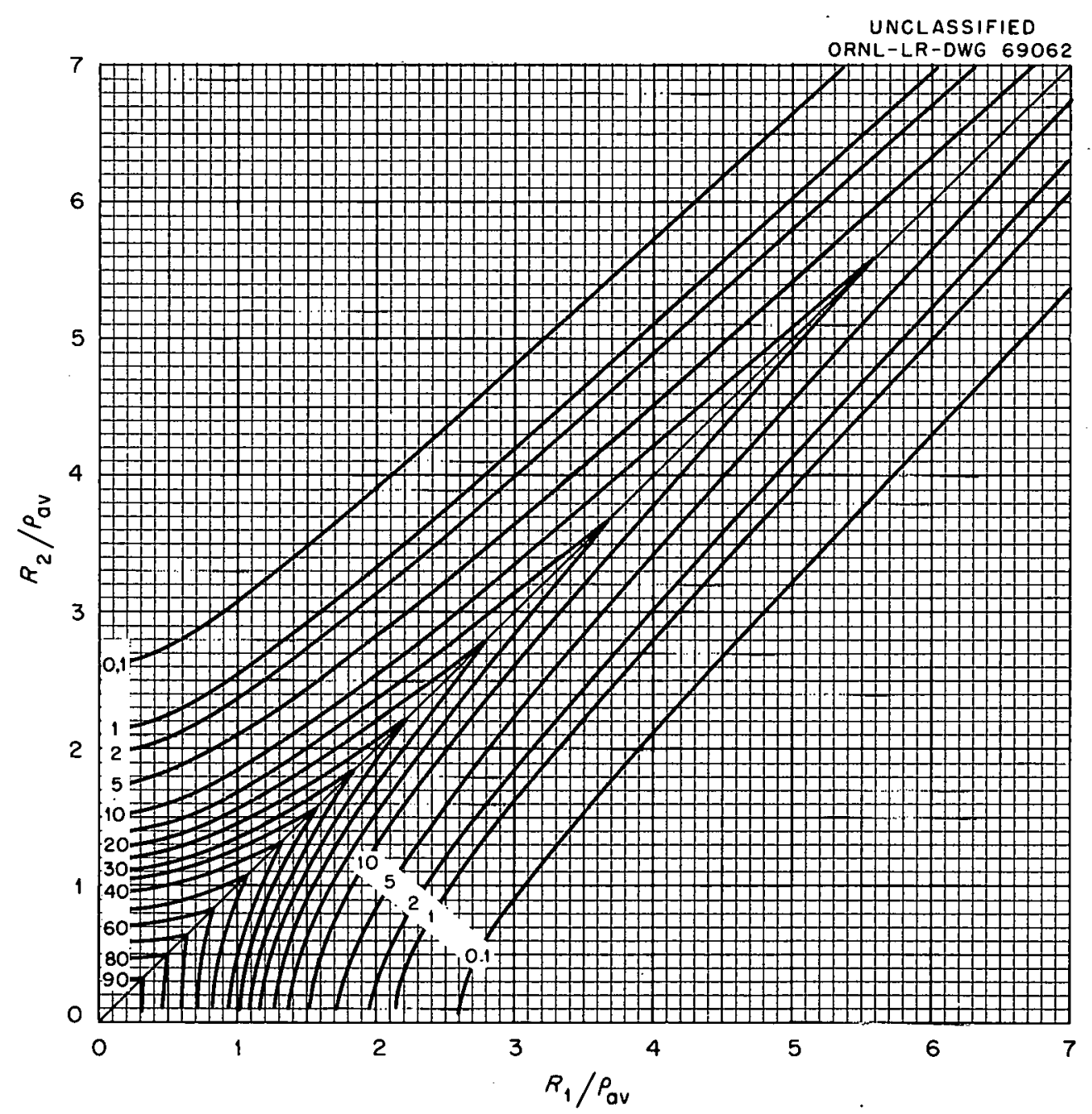

Fig. 18. Multiple-Scattering-Loss Map. Loss corituurs are in percent. 


\section{Appendix 1 \\ ROOT-MEAN-SQUARE MULTIPLE-SCATTERING ANGLE PROGRAM}

By making the appropriate substitutions in Eq. (7), the expression for $\chi_{c}^{2}$ becomes

$$
X_{c}^{2}=\left(1.810 \times 10^{-10}\right) t z^{2} Z^{2}\left(1-\beta^{2}\right) / A \mu^{2} \beta^{4}
$$

and the expression for $B$, from Eqs. (5) and (6), becomes

$$
e^{B} / B=\left(1.45+10^{5}\right) t \gamma^{2} /\left(1+3.33 \gamma^{2}\right) A Z^{2 / 3}
$$

In the above equations, $t$ is the thickness of the scatterer in $\mathrm{mg} / \mathrm{cm}^{2}, Z$ is the nuclear charge of the scatterer, $A$ is thc atomic weight of the scatterer in atomic mass units, $z$ is the charge of the particle, $\mu$ is the reduced mass of the particle, $\beta=v / c$ of the particle, and $\gamma=z Z / 137 \beta$.

Since in many cases the particle will lose a significant amount of energy in traversing the scatterer, the program calculates $\chi_{c}^{2}$ and $B$ for the $\beta$ corresponding to the average energy of the particle traversing the foil. The program computes the final cnergy of lle particle after passing through the scattering foil, the quantity required to calculate the average $\beta$, by calling a $d E / d x$ subroutine. The FORTRAN listing of this $d E / d x$ subroutine is given in Appendix II.

The program calculates the quantity $B$ by setting $B=4.4$, computing the value of $e^{B} / B$, and comparing this value with the right side of $\mathrm{Eq}$. (13). If the value is less than the right side, $B$ is incremenced in steps of 0.1 until the left side ic equal to thi iiglıl side. The value of $B$ thus determined is accurate to within 1 or $2 \%$, which is more than sufficient for the purpose of this work. If the value of $e^{B} / B$, when $B=4.4$, is found to be greater than the right side of Eq. (13), the particle has not undergone sufficient collisions to make the Moliere theory of multiple scattering applicable, and the program will print out the message B LESS THAN 4.5 - THEORY NOT VALID.

A typical output sheet from the program is shown in Fig. 19. The top two lines of the heading identify the particular case being computed. With the initial conditions as given by the second line, that is, the cliarge and mass of the particle and of the scatterer and the mean ionization potential of the scatterer, the root-mean-square multiple-scattering angle is computed for as many combinations of initial energy and scatterer thicknesses as desired. The program outputs a list of the initial energy, the scatterer thickness, the final energy as computed by the $d E / d x$ subroutine, the value of $B$ from Eq. (13), using the average value of $\beta$, the value of $\chi_{c}^{2}$ from $E q .(12)$, using the average value of $\beta$, and the value of $\theta_{\mathrm{av}}$ from the square root of the product of $B$ and $\chi_{c^{-}}^{2}$ This last column is labeled MOLIERE RMSSA. The program also computes, for the sake of comparison, the value of $\theta_{\mathrm{av}}$ from Eq. (9) of Dickinson and Dodder, ${ }^{1}$ which employs a nonrelativistic range-energy equation due to Bethe, and this column is labeled BETHE RMSSA. The values in the column MOLIERE RMSSA were used for Figs. 1-16.

The input to the program consists of four types of cards:

The Title Card. - This card contains any desired alphanumeric information to identify the case. The contents of this card are printed out in the first line of the heading for each page. For the output slieet shown in Fig. 19, the title card contained the words PROTONS ON COPPER. 
RMS MULTIPLE SCATIERING ANGLE FOR PROTONS ON COPPER

PART Z\#1. PART A\# 1. SCAT Z\#29. SCAT A\# 64. SCAT I\#371.0

$\begin{array}{ccccccc}\text { INITIAL } & \text { SCATIERER } & \text { FINAL } & \text { MOLIERE } & \text { MOLIERE } & \text { MOLIERE } & \text { BETHE } \\ \text { ENERGY } & \text { THICKNES } & \text { ENERG } & \text { B } & \text { CHI2 } & \text { RMSSA } & \text { RMSSA } \\ 70.00 & 0.5 & 69.997 & \text { B IS LESS THAN } 4.5-\text { THEORY NOI VALIO } \\ 70.00 & 1.0 & 69.994 & 5.2 & 1.17 E-07 & 0.000778 & 0.000771 \\ 70.00 & 2.0 & 69.988 & 6.0 & 2.33 E-07 & 0.001183 & 0.001172 \\ 70.00 & 3.0 & 69.982 & 6.5 & 3.50 E-07 & 0.001508 & 0.001494 \\ 70.00 & 5.0 & 69.969 & 7.1 & 5.83 E-07 & 0.002034 & 0.002015 \\ 70.00 & 10.0 & 69.939 & 7.9 & 1.17 E-06 & 0.003035 & 0.003007 \\ 70.00 & 20.0 & 69.878 & 8.7 & 2.33 E-06 & 0.004507 & 0.004465 \\ 70.00 & 30.0 & 69.816 & 9.1 & 3.50 E-06 & 0.005647 & 0.005594 \\ 70.00 & 50.0 & 69.694 & 9.7 & 5.85 E-06 & 0.007533 & 0.007463 \\ 70.00 & 70.0 & 69.571 & 10.1 & 8.21 E-06 & 0.009103 & 0.009018 \\ 70.00 & 100.0 & 69.387 & 10.5 & 1.18 E-05 & 0.011108 & 0.011004 \\ 70.00 & 200.0 & 68.769 & 11.2 & 2.37 E-05 & 0.016294 & 0.016139 \\ 70.00 & 300.0 & 68.148 & 11.7 & 3.59 E-05 & 0.020486 & 0.020289 \\ 70.00 & 500.0 & 66.893 & 12.3 & 6.08 E-05 & 0.027357 & 0.027088 \\ 70.00 & 700.0 & 65.621 & 12.6 & 8.67 E-05 & 0.033058 & 0.032726 \\ 70.00 & 1000.0 & 63.675 & 13.0 & 1.27 E-04 & 0.040700 & 0.040293\end{array}$

Fig. 19. Output Listing from the Root-Mean-Square Multiple-Scattering-Angle Program. 
The Primary Data Card. - This card inputs the particle charge, the particle mass, the scatterer charge, the scatterer mass, and the scatterer mean excitation potential (in units of ev) in five successive fields of eight columns each. The decimal point'is assumed to be at the right edge of each field unless it is specifically entered. One of these cards is required for each title card.

The Secondary Data Cards. - Data are read from the first nine fields of eight columns each. The first field contains the initial energy of the particle, and the remaining eight fields contain the desired thicknesses of the absorber. The calculation will be performed for every entry of absorber thickness. As many of the se cards as needed can follow the title and primary card. The program will ignore blank fields corresponding to no scatterer, but each of these secondary cards must have the particle energy in the first field.

The Control Card. - Normally the program will print 25 lines of information from the cases on the secondary data cards and then begin a new page, repeating the heading of the previous page. If it is desired to change the information on the title and the primary data card, a control card containing a 0 in the first eight-column field must be inserted before the new title card. In addition, the control card allows a certain flexibility in the output of the information from the secondary cards. By placing a control card containing a -1 in the first field before a secondary data card, the information from the secondary data card will be printed on a new page. This allows groups of secondary data cards to produce separate pages of output without inserting a new title and primary card.

The values of the mean ionization potential used in this work are given in Table 1. The FORTRAN listing for the program is shown in Table 2.

Table 1. Mean lonization Potentials Used to Compute Energy Losses

\begin{tabular}{lcc}
\hline Scatterer Material & $I(\mathrm{ev})$ & Source \\
\hline Nitrogen & 80.5 & $a$ \\
Aluminum & 166 & $b$ \\
Argon & 207 & $a$ \\
Copper & 371 & $b$ \\
Silver & 585 & $b$ \\
Gold & 1037 & $b$ \\
\hline
\end{tabular}

$a_{W}$. A. Aron, B G. Hoffman, and F. C. Williams, AECU -663 , UCRL121 (1949). (1957).

${ }^{b}$ H. Bichsel, R. F. Mozley, and W. A. Aron, Phys. Rev. 105, 1788 
Table 2. FORTRAN Listing for the Root-Mean-Square Multiple-Scattering-Angle Program

C PROGRAM FOR CCMPUTING RMS MULTIPLE SCATTERING ANGLE

C SECOND REVISICN I-MAR-1962 J.B.BALL

DIMENSION TITLE(I0), SCAT (8), DUMMYI (1,0), DUNMY $2(40)$, DUMMY3140)

II READINPUTTAPEIO,41, TITLE,PZ,PA,SZ, SA, SI

12 WRI TECUTPUTTAPE9, 43, TITLE,PZ,PA,SZ,SA, S I LHO

I 3 READINPUTTAPEI0,42, EI, (SCAT(I), I\#1,8)

IFIEI) $12,11,14$

11. REOPA \#PA $S A /(P A+S A)$

SZTTPHSZ*0.6666667

DC24IHI,8

IF(SCATII) $24,24,15$

15 STHSCAT(I)

NAI

CALL SDEDXIPZ,PA,EI,SZ,SA,SI,ST,N,NLIM, DUMMYI,

1 DUNMY 2 , DUMMY $3, E F)$

IF(EF) $24,24,16$

$16 \mathrm{NH}(12.0 * \mathrm{EI} / \mathrm{EF})-11.0$

IF $(N-2) 18,17,17$

17 CALL SDEDXIPZ,PA, EI,SZ,SA,SI,ST,N,NLIM, DUMMYI, IDLNMY2, DUMMYZ,EF)

IF (EF) $24,24,18$

$18 E A \#(E I+E F) / 2 . C$

RETAZH1.0-1931.1/((EA/PA)+931.1)1**2

ALPHA2\#( $(S Z * P Z / 137.0) * 2) / B E T A 2$

$L \# L+1$

IF $(L-25) 20,19,19$

19 WRITECUTPUTTAPE9, 43 , TITLE, PZ,PA,SZ,SA, SI. $L \# \cap$

20 RHS\#(1.243E5)*ST*ALPHA2/(SAESZTTP*(1.Ü+3.33*ALPHA2))

B\#4. 4

CLHS\#(EXPF(B))/B

IF(CLHS-RHS) $22,21,21$

21 WRITECUTPUTTAPE9, 44, EI, ST, EF

GCTO24

$22 B \# B+0.1$

CLHSH (EXPF (B)) /B

I F (CLHS-RHS) $22,23,23$

$23 \mathrm{CHI} \#(1.81 E-1 \mathrm{C}) * S T *(1,0-B E T A 2) *((P Z * S Z /(R E D P A * B E T A 2)) * 2) / S A$ RNSSA\#SQRTF (B*CHI 2$)$

BRMSSAHSQRTF( (R*SZ I, OGFIEI/EF))

1(7360.0*PA*LOCF (297.0*SGRTF(BETA2/SZ))1)

WRITECUTPUTTAPE9, $45, E$ I , ST, EF, B, CHI2, RMSSA, ERMSSA

24 CONTINUE

GCTOI3

41 FCRMAT(10A6/5F0.0)

42 FCRMAT (9F\&.C)

43 FORMAT 35 HIIRMS MULTIPLE SCATTERING ANGLE FCR, 10A6/IHO, $13 \times 7 H P A R T$ Z\#F3.0,4X7HPART A\#F3.0,4X7HSCAT Z\#F3.0, $24 \times 7$ HSCAT A\#F4.0,4X7HSCAT I\#F5.1//9HO INITIAL, $33 \times 9 H$ HCATTERER, $3 \times 5$ HFINAL, $4 \times 7 H M C L$ I ERE, $3 \times 7 H M C L I E R E$, $45 \times 7 H M C L I E R E, 6 \times 5 \mathrm{HBETHE} / 8 \mathrm{H}$ ENERGY, $4 \times 9 H T H I C K N E S S$, $53 \times 6 H E N E R G Y, 6 \times 1 H E, 7 \times 4 H C H I 2,8 \times 5 H R M S S 1,7 \times 5 H R M S S A)$

44 FCRMATIIHO,FR.2,3XF7.1,3XF\&,3, $16 \times 37 H B$ IS LESS THAN 4.5 - THEORY NOT VALID)

45 FORMAI (IHJ,F8.2,3XF7.1,3XF8.3,4XF5.1,4XIPE8.2,4XOPF8.6,4XF8.6) END $(1,1,0,0,0,0,0,0,0,0,0,0,0,0,0)$

15880108

15880109

$\mid 5880111$

15880113

15880115

15880117

15880119

15880121

15880123

15880124

15880125

15880202

15880204

1588025.6

15880208

15880210

15880212

15880214

15880215

15880216

15880218

15880220

15880222

15884224

15880302

15880304

15880306

15880308

$1588031 \mathrm{C}$

15880312

15880314

15880316

15880318

15880320

15880322

1588032.4

15880402

15890404

15880406

15880408

$1588041 \mathrm{C}$

15880411

15880413

$1588041 \mathrm{~b}$

15880417

15880420

15880422

15880502

15880504

15880506

15880508

15880510

15880512

15880514

15880516

15880518 


\section{Appendix II}

\section{THE $d E / d x$ SUBROUTINE}

This is a general-purpose subroutine which employs a form of the $d E / d x$ expression similar to that used by Aron, Hoffman, and Williams, ${ }^{5}$

$$
-\frac{d E}{d x}=\frac{4 \pi e^{4} z^{2}}{m v^{2}} N Z\left[\ln \frac{2 m v^{2}}{l}-\ln \left(1-\beta^{2}\right)-\beta^{2}\right]
$$

where $e$ is the electron charge, $m$ is the electron mass, $v$ is the velocity of the charged particle, $z$ is the charge of the particle, $\beta=v / c$ for the charged particle, $I$ is the mean excitation potential of the stopping material, and $N Z$ is the number of electrons per unit volume of the stopping material.

With appropriate substitutions, the formula is reexpressed for this work as

$$
-\frac{d E}{d x}=\left(3.071 \times 10^{-4}\right) \frac{z^{2} Z}{\beta^{2} A}\left[\ln \left(\frac{1.022 \times 10^{6}}{1-\beta^{2}}\right) \frac{\beta^{2}}{l}-\beta^{2}\right],
$$

where the only new definitions are $Z$ and $A$, the atomic number and atomic weight, in atomic mass units, of the stopping material. The value of the mean excitation potential $l$ is in electron volts, and $d E / d x$ has the units of $\mathrm{Mev} / \mathrm{mg} \mathrm{cm}^{-2}$. Note that this form of the energy-loss equation does not contain the shell correction terms necessary at very low energies or the density factor necessary for very high energies. ${ }^{6}$

The program computes, by performing a numerical integration, the energy of a particle after the particle traverses an absorber. The absorber is divided into a number of increments. At each increment the program uses the initial particle energy to calculate a value of $d E / d x$ and to estimate the particle energy after the absorber increment. This estimated energy is then used to obtain the average energy of the particle in traversing the increment. The $d E / d x$ corresponding to this average energy is then used to compute the $f$ inal particle energy after the absorber increment. The final energy is then used as the initial energy for the next increment. The entire process is repeated for each increment of the absorber.

The FORTRAN listing for the program is given in Table 3. Information is inputed and outputed from the subroutine by means of the argument list: PZ, PM, EINIT, ABSZ, ABSA, ABSI, ABSTH, N, NLIM, E, DEDX, RTABS, EFINAL. The first eight quantities are input required by the subroutine and are, in order, the charge of the particle, the mass of the particle in atomic mass units, the initial energy of the particle in Mev, the atomic number of the absorber material, the atomic weight of the absorber material in atomic mass units, the mean ionization potential of the absorber in ev, and the number of increments desired for the numerical integration. The last five quantities in the list are output from the subroutine. If the thickness of the absorber exceeds the range of the particle, the subroutine will return control to the calling program as soon as the particle energy becomes negative. In this case the

\footnotetext{
${ }^{5}$ W. A. Aron, B. G. Hoffman, and F. C. Williams, AECU-663, UCRL-121 (1949).

${ }^{6}$ R. M. Sternheimer, Phys. Rev. 115, 137 (1999).
} 
value of NLIM is the number of the absorber increment causing the energy to go negative. The next three quantities in the list are arrays. The array $E$ contains the initial particle energy before the particle tra* verses each absorber increment, the array DEDX contains the value of $d E / d x$ corresponding to each entry in the E array, and the array RTABS contains the total absorber traversed to reach the corresponding energy in the $\mathrm{E}$ array. The final argument in the list, EFINAL, is the particle energy after the particle traverses the entire absorber.

In the root-mean-square multiple-scattering program only the final particle energy is of interest, and no use is made of the array information. The value of $N$ is set by the program and depends on the thickness of the absorber.

The root-mean-square multiple-scattering angle program chooses $N$ in the following way: The subroutine is called with $N$ set equal to 1 . The final energy calculated is returned to the program, and the value of $N$ for the numerical integration is then obtained from the expression

$$
N=12\left(\frac{\text { EFINAL }}{\text { EINIT }}\right)-11
$$

The value of $N$ is restricted by the program to be a maximum of 40 . This provides sufficient accuracy over the energy range of interest in this program.

For use in other programs, the size of the E, DEDX, and RTABS arrays may be easily enlarged by changing the dimension statement.

Table 3. FORTRAN Listing for the $d E / d x$ Subroutine

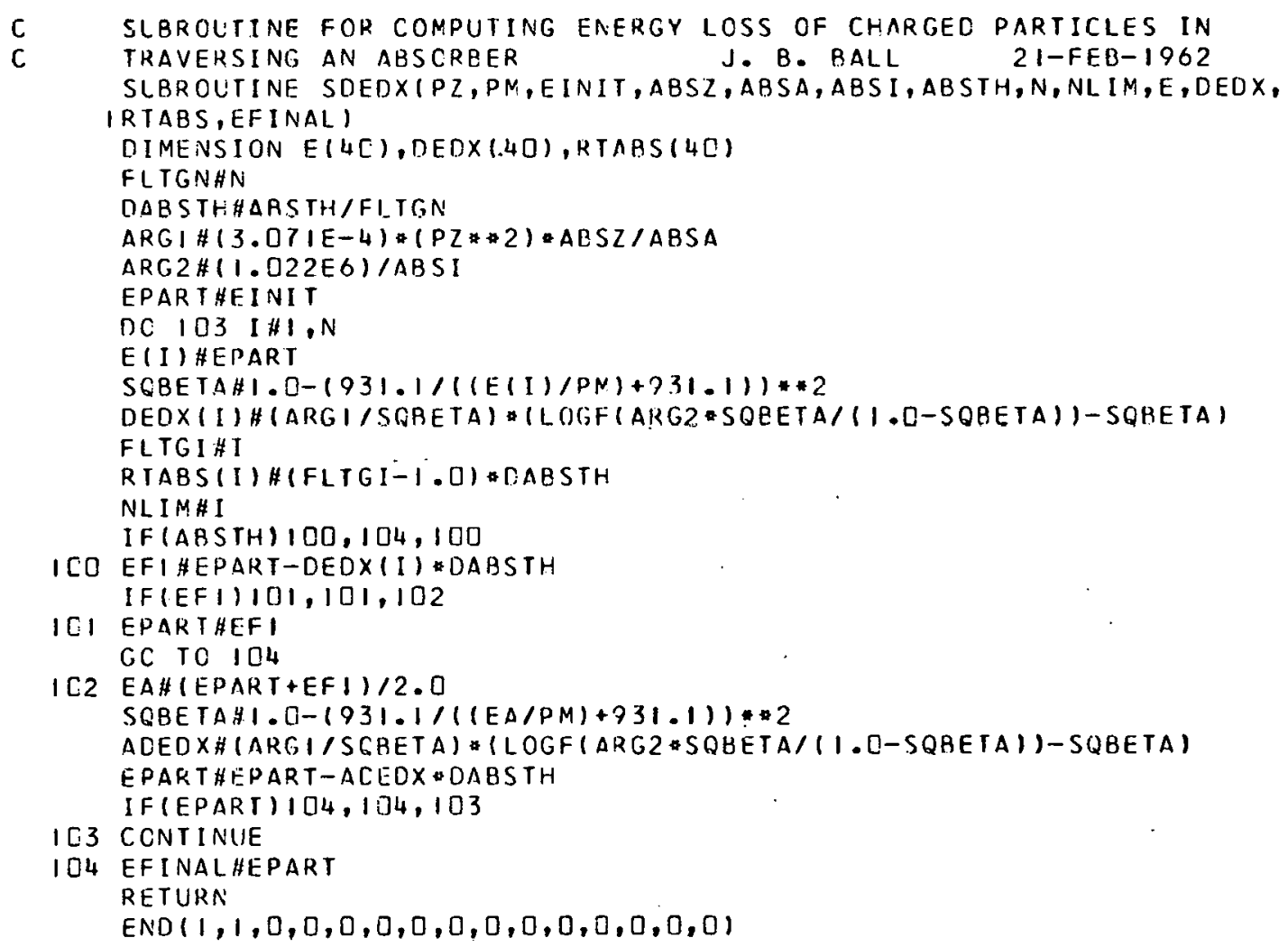




\section{Appendix III \\ PROGRAM FOR COMPUTING MULTIPLE-SCATTERING LOSSES}

The problem of performing the numerical integration can be easily seen from Fig. 17. The vector $r_{1}$ defines a point on the scatterer surface which has a maximum radius of $R_{1}$. The vector $r_{2}$ defines a point on the detector surface which has a maximum radius of $R_{2}$. The probability per unit area of multiple scattering from the point $r_{1}$ to the point $r_{2}$ is given by $\mathrm{Eq} .(11)$ and the vector difference $\rho$. It is necessary to calculate the probability at each value of $r_{2}$ from all points throughout the range of $r_{1}$ and $\Phi$. The total fraction of particles passing through the scattering foil and scattering inside the detector aperture will then be the sum of all the probabilities properly normalized for the areas. For this computation, the scatterer and detector areas are divided into small-area elements, and the value of $\rho$ is calculated for the distance between the centers of these elements,

In the first program these area increments were all chosen to be the same for the respective apertures. Although this made the normalization easier, it was found to be rather cumbersome, since a large number of radial divisions were required to obtain a significant number of divisions near the center of the apertures. In the program used to construct Fig. 18, the radii of the respective apertures were divided into a number of equal lengths and the areas computed for each area segment.

The scatterer radius $R_{1}$ is divided into $N$ parts. The average radius for the $n$th annulus on the scatterer surface will then be

$$
r_{1}(n)=(n-1 / 2) R_{1} / N
$$

Similarly, the detector radius is divided into $M$ parts, and the average radius for the mth annulus on the detector surface will be

$$
r_{2}(m)=(m-1 / 2) R_{2} / M
$$

and the outer diameter of each detector annulus is

$$
R_{2}^{\prime}(m)=m R_{2} / M \text {. }
$$

Since there is symmetry about $\Phi=180^{\circ}$, $\Phi$ being the angle between the two radius vectors, $\Phi$ need only be incremented from 0 to $\pi$ and the resulting sum doubled. The angle $\Phi$ is divided into $2 I$ parts, and the $i$ th angle between radius vectors is

$$
\Phi(i)=(i-1 / 2) \pi / I
$$

This particular method of incrementing $\Phi$ is chosen so that the symmetry about $\Phi=\pi$ is readily separable. The value of the root-mean-square displacement $\rho$ is a function of the two average radius vectors and the angle between them and is solved for by the law of cosines:

$$
\rho^{2}=r_{1}^{2}(n)+r_{2}^{2}(m)-2 r_{1}(n) r_{2}(m) \cos \Phi(i) .
$$

The total probability for scattering into the detector aperture is

$$
\Pi=2 \sum_{m=1}^{M} \sum_{n=1}^{N} \sum_{i=1}^{l} P(\rho) \cdot A \cdot F,
$$


where $P(\rho)$ is the probability per unit area for multiple scattering with a root-mean-s quare displacement of $\rho$ as given by Eq. (11), $A$ is the area of the detector segment, and $F$ is the fractional area of the scatterer surface represented by the scatterer segment. The quantity $F$ normalizes the incident particle flux to unity.

The area of each annulus on the scatterer surface defined by a given $r_{1}(n)$ is

$$
a_{1}(n)=2 \pi r_{1}(n) R_{1} / N
$$

Since the total area of the scatterer is $\pi R_{1}^{2}$, the fractional contribution from each annulus will be

$$
f_{1}(n)=2 r_{1}(n) / R_{1} N
$$

Each annulus is divided into $2 I$ parts, so that the fractional area of each scatterer is

$$
F=r_{1}(n) / R_{1} N I \text {. }
$$

Similarly, the area of each detector annulus is

$$
a_{2}(m)=2 \pi r_{2}(m) R_{2} / M
$$

This is also divided into 21 parts, each of which will receive an identical flux of scattered particles due to the symmetry about the central axis. However, since the total contribution over the entire annulus simply requires multiplying by the number of parts of the annulus, in this calculation the entire annulus can be taken as the area segment of the detector surface:

$$
A=2 \pi r_{2}(m) R_{2} / M \text {. }
$$

Substituting Eqs. (11), (25), and (27) into Eq. (22), the probability for scattering into the detector aperture becomes

$$
\Pi=\frac{4 R_{2}}{\rho_{\mathrm{av}} R_{1} M N I} \sum_{m=1}^{M} r_{2}(m) \sum_{n=1}^{N} r_{1}(n) \sum_{i=1}^{l} \exp \left(\frac{-\rho^{2}}{\rho_{\mathrm{av}}^{2}}\right) .
$$

With the aid of Eqs. (17) and (18) this simplifies to

$$
\Pi=\frac{4 R_{2}^{2}}{\rho_{\mathrm{av}}^{2} M^{2} N^{2} I} \sum_{m=1}^{M}(m-1 / 2) \sum_{n=1}^{N}(n-1 / 2) \sum_{i=1}^{I} \exp \left(\frac{-\rho^{2}}{\rho_{\mathrm{av}}^{2}}\right) .
$$

This program utilizes the form of the equation given by (28), because it is possible to extract more information from this form. The partial sum at each value of $m$ will correspond to the contribution inside a detector area of radius $R_{2}^{\prime}(m)$ given by Eq. (19). Thus, for any given value of the scatterer radius $R_{1}$, the program will compute the multiple-scattering loss for detector apertures corresponding to each division of $R_{2}$.

An output listing from the program is shown in Fig. 20. The heading outputs the following quantities: CASE, an identification number; RMSSA, the root-mean-square multiple-scattering angle characterizing the distribution; SRMAX, the radius of the scatterer denoted above as $R_{1}$; DRMAX, the radius of the detector denoted above as $R_{2} ; D$, the distance between the foils measured in the same units as $R_{1}$ and $R_{2} ; \mathrm{MI}$, the number of angular increments from $\Phi=0$ to $\pi ; \mathrm{MN}$, the number of divis ions of the scatterer radius; MM, the number of divisions of the detector radius; RHOAV, the value of $\rho_{\mathrm{a}}$ 
PROGRAM FOR NUMERICAL INTEGRATION WITH CONSTANT RADIAL INCREMENT

\begin{tabular}{|c|c|c|c|c|c|}
\hline CASE\#:D & & ASSA\#0.0100 & SRMAXH 1.0 & DRMAX\# 4.0 & . D\# 100.00 \\
\hline$M 1 \# 10$ & MNH 20 & MM\# 80 & RHOAV\# 1.000 & $\therefore$ ASRMAX\# 1.00 & RTP\#1.0001250 \\
\hline INDEX M & & $D R(M)$ & PROB (M) & TPROB (M) & TLOSSIM) \\
\hline 1. & & 0.050 & 0.15804 & 0.15804 & 36.782 .45 \\
\hline 2 & & 0.100 & 0.47275 & 0.63080 & 36.920 .32 \\
\hline 3 & & 0.150 & 0.78334 & 1.414 .14 & $37 . .14935$ \\
\hline 4 & & 0.200 & 1.08713 & 2.50126 & $37.46838^{\prime}$ \\
\hline 5 & & 0.250 & 1.38150 & 3.88276 & 37.8758 .3 \\
\hline 6 & & 0.300 & 1.66397 & 5.54673 & 36.36966 \\
\hline 7 & & 0.350 & 1.93221 & 7.47894 & 38.94744 \\
\hline 8 & & 0.400 & 2.18406 & 9.66299 & 39.60628 \\
\hline 9 & & 0.450 & 2.41756 & 12.08055 & 40.34296 \\
\hline 10 & & 0.500 & 2.63099 & 14.71154 & 41.15384 \\
\hline 11 & & 0.550 & 2.82288 & 17.53441 & 12.03500 \\
\hline 12 & & 0.600 & $2.992 \pi 2$ & 20.52643 & 42.98214 \\
\hline 13 & & U.650 & 3.13748 & 23.66391 & 43.99074 \\
\hline 14 & & 0.700 & 3.25865 & 26.92256 & 45.05600 \\
\hline 15 & & 0.750 & 3.35517 & 30.27773 & 46.17292 \\
\hline 16 & & 0.800 & 3.42701 & 33.70475 & 4.7 .33633 \\
\hline 17 & & 0.850 & 3.47442 & 37.17917 & 48.54094 \\
\hline 18 & & 0.900 & 3.49793 & 40.67711 & 49.78135 \\
\hline 19 & . & 0.950 & 3.49834 & 44.17544 & 51.05214 \\
\hline 20 & & 1.000 & 3.47668 & 47.65212 & 52.34788 \\
\hline 21 & & 1.050 & 3.43424 & 51.08636 & 48.91364 \\
\hline 22 & & 1.100 & 3.37247 & 54.45883 & 45.54117 \\
\hline 23 & & 1.150 & 3.29303 & 57.75186 & 42.24814 \\
\hline $2 !$ & · & 1.200 & 3.19768 & 60.94953 & 39.050117 \\
\hline 25 & & 1.250 & 3.088 .30 & 64.03783 & 35.96217 \\
\hline 26 & & 1.300 & 2.96685 & 67.00468 & 32.99532 \\
\hline
\end{tabular}

Fig. 20. Output Listing from the Multiple-Scattering-Loss Proyram. 
from Eq. (21); ASRMAX, the dimensionless measurement of the scatterer aperture $R_{1} / \rho_{\text {av }}$; RTP, the total fraction of particles within the detector radius DRMAX.

For a sufficiently large value of DRMAX, the value of RTP becomes a measure of the accuracy of the numerical integration, since the distribution over all space should normalize to unity.

The output also lists four quantities as a function of the index $m$ of the partial sum. The column headed DR $(m)$ is the detector radius corresponding to the value of $m$ and is given in the dimensionless units $R_{2}^{\prime}(m) / \rho_{\text {av }}$. Each value of $\mathrm{DR}(m)$ can be considered as a separate $R_{2} / \rho_{\mathrm{av}}$. The column headed $\mathrm{PROB}(m)$ represents the scattering into the detector annulus defined by the value of $m$. The column headed TPROB $(m)$ represents the probability for scattering into all annuli of the detector surface up to and including the $m$ th, that is, the probability for scattering inside a detector radius of the corresponding $\operatorname{DR}(m)$. The column headed $\operatorname{TLOSS}(m)$ is the probability for losing particles by scattering outside the detector radius given by $\mathrm{DR}(m)$. For all values of $\mathrm{DR}(m)$ greater than the scatterer radius, the value of $\operatorname{TLOSS}(m)$ is simply

$$
\operatorname{TLOSS}(m)=1-\operatorname{TPROB}(m) .
$$

When the detector radius is smaller than the scatterer radius, the probability for losing particles is corrected for the fraction of the scatterer not subtended by the detector in the case of no scattering. For these cases,

$$
\operatorname{TLOSS}(m)=1-\operatorname{TPROB}(m)\left[R_{1} / R_{2}^{\prime}(m)\right]^{2} .
$$

All probabilities are printed out as percent.

The results of the computation shown in Fig. 20 are plotted graphically in Fig. 21 . This figure can be compared with Fig. 2 of ref 1.

The probability of losing particles is always a maximum when $R_{1}=R_{2}$. The probability of losing particles as a function of $R_{1} / \rho_{\mathrm{av}}$ when $R_{1}=R_{2}$ is shown in Fig. 22. The map in Fig. 18 was constructed with the aid of Fig. 22 and many different figures of the type shown in Fig. 21.

The FORTRAN listing of the numerical integration program is given in Table 4. The input to the program consists of one card per case. The card is divided into eight fields of eight columns each. 'The fields are in the order: CASE, RMSSA, SRMAX, DRMAX, D, MI, MN, MM, where these quantities have been defined in the output description. The values of CASE, MI, MN, and MM must be integers. For all the remaining fields the decimal point is assumed to be at the right edge of the field unless it is specifically entered. The quantity RMSSA is in units of radians.

Experience has shown that MI $=20$ is a sufficient number of angular divisions for the area covered in Fig. 18. The radial divisions MM and MN may vary from 20 to 100, depending on the aperture size. An approximate running time for the program may be estimated by the relationship

$$
\text { running time }=2(M I)(M N)(M M) \text { msec. }
$$




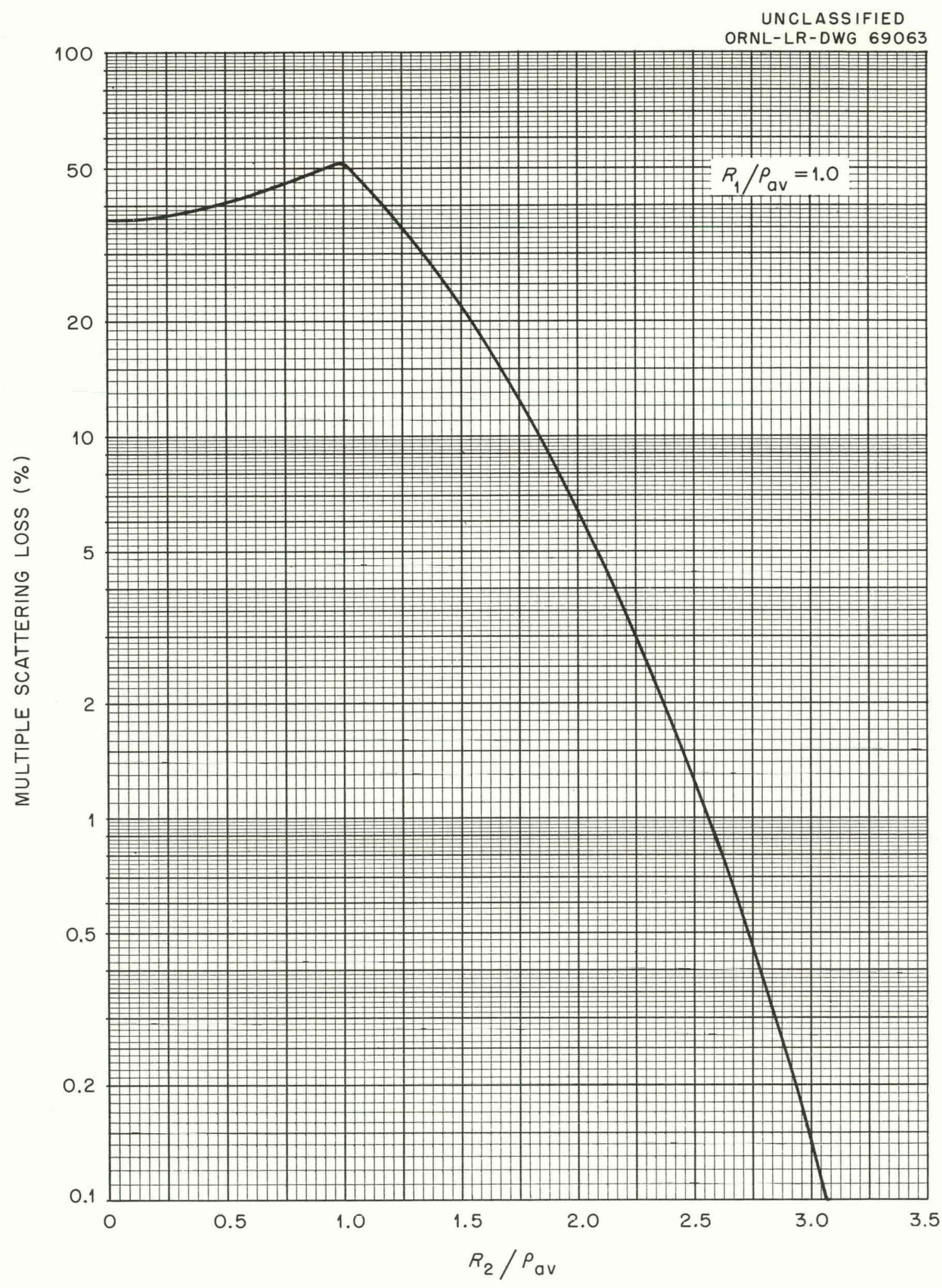

Fig. 21. Multiple-Scattering Losses as a Function of $R_{2} / \rho_{\text {av }}$, when $R_{1} / \rho_{\text {av }}=1.0$. 


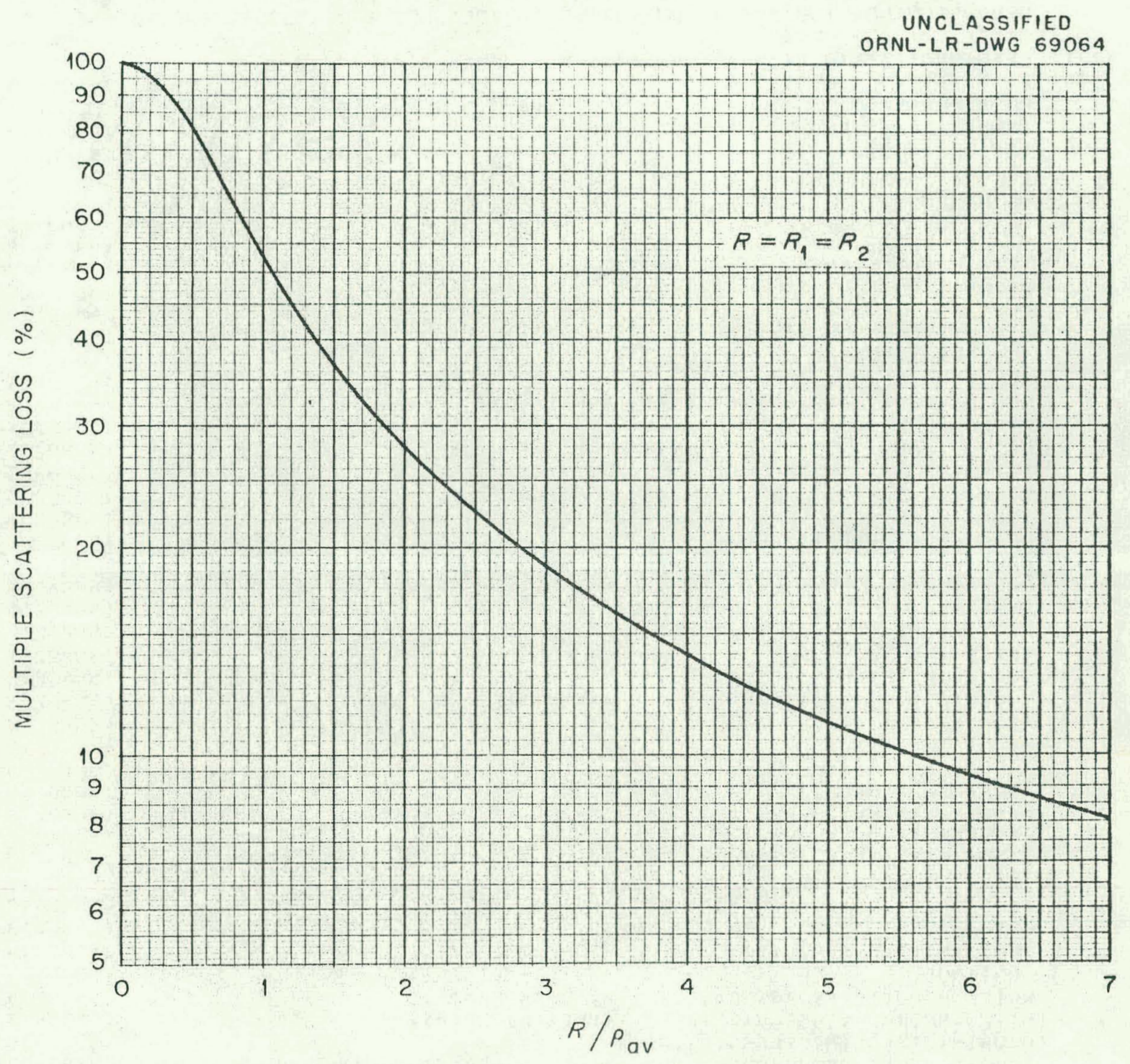

Fig. 22. Multiple-Scattering Losses as a Function of $R / \rho_{a v^{\prime}}$ when $R=R_{1}=R_{2}$. 
Table 4. FORTRAN Listing for the Multiple-Scattering-Loss Program

C PROGRAM FOR NUMERICAL INTEGRATION WITH CONSTANT RADIAL INCREMENT I588DIDB 10) DIMINS I ONINDEX (300), ASR (300), DR (30U), PROB (3UD), TPROB (300), TLOSS (3015880108

II READINPIITTAPEIU, 41 , NCASE, RMSSA, SRMAX, DRMAX, D, MI, MN, MM

41 FORMAT $(19,4 \mathrm{FB}, 0,318)$

RHOAVHRMSSA*D

ASRMAXHSRMAX/RHOAV

$A 2 H 1.0 /(R H O A V * 2)$

FLT GMI HMI

TI TRIMNHMN

I L I $1494 M$ MM

FI 13.3 .111593

SRIHSRMAX/FLIGMN

DOJIINH I, MN

TLTGNHN

20 ASR (N) H (FLIGN-0.'S) *SHI

DRIADRMAX/TLTGMM

DEI.TAHPI/FLTGMI

SNIIRMH4. D*A2 \#DRI. SRI/(FLTGMI * SRMAX*\#2))

RTPROBHO. [.]

DOO23MHI, MM

FLTGMHM

BSHMHOT D

INDEXIMIAM

DR (M) H (FLTGMHDRI I/RHOAV

$A D R H(F L, T G M-0.5) \approx D R I$

DO22 NHI, MN

ASUMHO.O

חO2IIHI.MI

FL.TGIHI

THETAB IFLTGI-0 - 51 ) NDELTA

$R H O 2 \#(A S R(N) * 2)+(A D R * 2)-2.0 * A S R(N) * A D R * C O S F(T H E T A)$

APRORHEXPF $(-(A 2 * R H O 2))$

21 ASIIMHASIUM+APROB

BPROB\#ASR (N) *ASUM

22 BSUMHBSUM+BPROB

PROB (M) HSNORM ADR BSUM

RTPROBARTPROB+PROB (M)

IPROB (M) ARTPROB

IF(DR(M)-ASRMAX) $24,25,25$

$24 \mathrm{TLOSS}(M)$ H. O-TPROB $(M) *((A S R M A X / D R(M)) * 2)$ G0I023

25 TLOSS M) HI.U-TPROH(M)

23 CONTINUF

WRITEOUTPUTTAPEQ, 12 , NCASF, RMSSA, SRMAX, DRMAX, D, 15880108 15880109 15880110 15880111

15880112

15880114

15880115

15880116

15880117

15890118

15880119

15880120

15880121

15880407

15880123

15880124

15880408

15880201

15880202

15880203

15880204

15880205

15880206

$158804[59$

15880208

15880209

15880210

15880211

15880410

15880213

15880214

15890215

15880216

15880217

15880218

15880219

15880220

15880411

15880412

15880413

15000414

15880415

IMI, MN, MM, RHOAV, ASRMAX,RTPROB, I INDEX (M),DR (M),

15880416

15880417

IPROB (M), TPROB (M), TIOSS (M), MH I, MM)

15880418

42 FORMATIOTHI PROGRAM FOR NUMERICAL INTEGRATION WITH CONSTANT RAOIAI588O3O3

IL INCREMENT/ $/ 8110$ CASEHI3,5X6HRMSSA\#F6.4, 4 X6HSRMAX\#F5.1, 15880304 $15 \times 6$ HORMAXHF5.1,5X2HDHF $7.2 / 6 H O$ MIH13,2X3HMNH 3 ,

$12 \times 3$ HMMHI $3,4 \times 6$ HRHOAVHFG. 3, 4 X HASRMAXHFG. 2, 4 X4HR TPHF 9.711

I ICHO INDEX M, 8X5HDR (M), 8X7HPROB(M), 9X8HTPROB(M),?X8HTLOSS(M)/

1(1 $\mathrm{HC}, 4 \times 13,8 \times \mathrm{XPF} 7.3,7 \times 2 \mathrm{PF} 9.5,8 \times 2 \mathrm{PF} 10.5,7 \times 2 \mathrm{PF} 10.5))$

Gorol 1

END

15880419

15880427

15880421

15880422

15880309

15880310 
ORNL-3311

UC.34 - Physics

TID-4500 (18th ed.)

\section{INTERNAL DISTRIBUTION}

1. Biology Library

2-3. Central Research Library

4. Reactor Division Library

5-6. ORNL - Y.12 Technical Library Document Reference Section

7-56. Laboratory Records Department

57. Laboratory Records, ORNL R.C.

58. J. A. Auxier

59. J. K. Bair

60-84. J. B. Ball

85. R. E. Biggers

86. R. D. Birkhoff

87. L. N. Blumberg

88. R. W. Boom

89. J. W. T. Dabbs

90. A. Chetham-Strode

91. R. L. Ferguson

92. C. B. Fulmer

93. C. D. Guodman

94. E. E. Gross

95. R. L. Hahn

96. M. L. Halbert
97. F. T. Howard

98. C. E. Larson

99. G. Leibfried

100. R. S. Livingston

101. F. K. McGowan

102. J. A. Martin

103. E. Newman

104. R. H. Ritchie

105. H. W. Schmitt

106. M. J. Skinner

107. A. H. Snell

108. F. J. Walter

109. A. M. Weinberg

110. C. D. Zerby

111. A. Zucker

112. H. Feshbach (consultant)

113. W. A. Fowler (consultant)

114. M. Goldhaber (consultant)

115. M. S. Livingston (consultant)

116. J. R. Richardson (consultant)

117. J. H. Van Vleck (consultant)

118. J. A. Wheeler (consultant)

119. Rescarch and Development Division, AEC, ORO

120-748. Given distribution as shown in TID-4500 (18th ed.) under Physics category ( 75 copies - OTS) 